\title{
Un enterramiento múltiple del yacimiento calcolítico de Humanejos (Parla, Madrid) desde una perspectiva tafonómica: Agrupando y reagrupando la familia
}

\section{Multiple burial in pit from Humanejos site (Parla, Madrid). The Taphonomy as a source for the study of funeral rituals: Grouping and regrouping the family ${ }^{1}$}

Concepción Blasco, Corina Liesau, Patricia Ríos, José Luis Gómez y Raúl Flores

Recibido 05/06/2014

Aceptado 21/07/2014

\begin{abstract}
Resumen
El artículo da a conocer una fosa de enterramiento múltiple localizada en Humanejos (Parla, Madrid), un gran poblado de "silos" Calcolítico. Una primera parte se dedica al estudio antropológico y paleopatológico de ocho individuos inhumados en dos niveles. Los seis del nivel inferior pertenecen posiblemente a un mismo grupo familiar. En una segunda parte, a través del estudio tafonómico, se reconstruye la secuencia de inhumación que, a juzgar por el desplazamiento parcial de uno de los cuerpos, se realizó, al menos, en tres momentos diferentes. Los gestos de colocación y traslado estuvieron orientados a reproducir una escenografía dedicada a destacar los roles desempeñados por algunos de los miembros del grupo.
\end{abstract}

Palabras clave: Calcolítico, colectivismo funerario, Tafonomía, Madrid.

\begin{abstract}
This contribution presents a multiple burial in pit from Humanejos site, a large Chalcolithic settlement located in Parla, Madrid. The first part deals with the anthropological and palaeopathological study of eight indivials buried in two stratigraphic levels. The six individuals from the lower level may belong to the same family. In a second part the taphonomic study reconstruct the sequence burial. This analysis shows that -given to the partial displacement of one of the bodies-, the burial took place at least three different times. Placement gestures and movements could be aimed to reproduce a scene dedicated to highlight the roles played by some of the group members.
\end{abstract}

Keywords: Chalcolithic, collective burial, Taphonomy, Madrid.

1 El trabajo ha sido realizado dentro del Proyecto: Las sociedades calcolíticas y su marco temporal en la región de Madrid. Una revisión a la luz de nuevos datos. Referencia:
Plan Nacional I+D+i 2008-2011 HAR 2011-28731. IP Corina Liesau.

corina.liesau@uam.es 


\section{INTRODUCCIÓN}

Aunque el origen de los enterramientos en fosas simples dentro de los poblados de "silos" se remonta al Neolítico, sin embargo los más antiguos acogen únicamente inhumaciones individuales y también dobles o incluso triples de enterramientos coetáneos. Pues aunque se conocen algunas con inhumaciones colectivas en hoyos, como las de Costamar en la región levantina (Flors, 2010: 179), de Paternanbidea en la Cuenca del Ebro (Beguiristain, et al., 2011: 230) o de varios sitios del Pirineo Oriental (Fernández Eraso, et al.2011:254), se trata de hoyos o fosas con enterramientos depositados a lo largo de un tiempo más o menos dilatado o y donde a menudo se practican desplazamientos y/o reducción de restos de inhumaciones previas.

En el III milenio, este tipo de enterramientos colectivos diacrónicos en hoyo se encuentran, en ocasiones en algunos poblados de silos con o sin recintos de fosos como La Pijotilla (Hurtado et al., 2002), Perdigoes (Valera et al., 2000), Valencina de la Concepción (Guijo y Lacalle, 2013) y otros (Márquez y Jiménez, 2010: 213-219), una modalidad a la que se suman los enterramientos múltiples simultáneos en tumbas-hoyo, los cuales se abandonan en el II milenio a. C. cuando, de nuevo, las inhumaciones simultáneas en una misma tumba-hoyo se reducen a dos o tres cuerpos. Así ocurre en la Región de Madrid durante el horizonte Protocogotas (1700-1400 AC) en el que predominan las inhumaciones dobles o individuales, como Caserío de Perales (Blasco, et al. 1991), La Dehesa (Macarro, 2000), la única tumba de esta cronología documentada en Camino de las Yeseras (Liesau et al., 2008) o varias tumbas de Los Berrocales (Aliaga y Megías, 2011).

Las primeras noticias sobre esta tipología en fosas simples ubicadas en los poblados de hoyos se remontan a finales del siglo XIX donde, de manera puntual, hay referencias bibliográficas particularmente de yacimientos del sur peninsular (Lizcano, et al. 1991-92: 20-21). Sin embargo, hasta hace unos años en la mayoría de los estudios sólo encontramos alusiones puntuales de las que no se puede deducir que se trate de un fenómeno tan generalizado, posiblemente debido a su escasa visibilidad y a la reducida extensión excavada en la mayoría de estos yacimientos en los que quedaron integradas. La tendencia ha cambiado en las últimas décadas cuando empiezan a tener presencia más explícita en las publicaciones relacionadas con este tipo de contextos y son objeto de estudio de forma más exhaustiva. (Fabián, 2006: 306-336; Pérez Jordá, et alii., 2011: 83-90, García Puchol, et al 2013). A pesar de estos avances, las tumbas múltiples calcolíticas con más de tres individuos siguen siendo poco conocidas, debido en; parte, a su reducido número y a la dificultad que entraña el distinguirlas de las tumbas colectivas con las que conviven, a no ser que se realice un estudio tafonómico.

\section{LAS TUMBAS CON INHUMACIONES MÚLTIPLES}

Desde hace ya un tiempo, se vienen denominando tumbas de enterramientos múltiples aquellas que contienen varias inhumaciones practicadas en un mismo acto fúnebre o en espacio temporal muy próximo y que, por tanto, reflejan un carácter "episódico" y, en consecuencia, son de cierta excepcionalidad, quedando intactas tras las exequias que acompañan al depósito de los cuerpos (Andrés, 1998: 152). La interpretación de una tumba con varios cuerpos como enterramiento múltiple tiene la dificultad que conlleva llegar a las apreciaciones tafonómicas que certifican la simultaneidad o, la proximidad temporal de las distintas inhumaciones (Chambon y Leclerc, 2007: 290).

Precisamente la falta de estas observaciones tafonómicas puede ser la causa de que muchas veces estos enterramientos simultáneos hayan quedado englobados dentro de la categoría de enterramientos colectivos diacrónicos sin explicitar su singularidad y sin prestar atención a la idea de la relación directa que, en vida, pudieron tener los miembros del grupo que no sólo se enterraron juntos, sino que su inhumación acaeció en un mismo momento. Pero los estudios de la Arqueología Forense han permitido avanzar sustancialmente en este tipo de aspectos (Haglund y Reay, 1993; Duday 1997; Haglund y Sorg, 1997 y Ubelaker, 2007).

Obviamente, todas estas prácticas adquieren matices singulares según las circunstancias que rodearon a la muerte y al lapso temporal que separa el fallecimiento de los diferentes individuos enterrados en una misma tumba. Ello acrecienta la necesidad de no descuidar su observación cuando se aborda una investigación relacionada con los rituales funerarios que acompañan a inhumaciones múltiples, tanto por su complejidad, como por su carácter excepcional.

A medida que vamos conociendo más ejemplos de esta modalidad de enterramientos, resulta más evidente que la mayoría de dichas tumbas acogen sobre todo inhumaciones femeninas con infantiles, o sólo femeninas, como una tumba con seis mujeres jóvenes de Camino de las Yeseras (Blasco y Ríos, 2006: 109-11; Gómez y Aliaga, 2010 y Ríos et al., 2012;) y, con menos frecuencia, lo que podrían ser familias nucleares aunque no faltan tampoco las que contienen una mayoría de varones, caso de El Tomillar (Fabián, 1995) o del enterramiento 1 de Cerro de las Cabezas (Fabián, 2006: 507-511). Teniendo en cuenta que, aunque no se explicite, la población acogida en estas tumbas múltiples está estrechamente relacionada con los enterramientos dobles o triples de mujeres con niños, de los que se asumía que eran enterramientos simultáneos, parece lógico pensar que ambas modalidades responden a unas causas $\mathrm{y} / \mathrm{o}$ necesidades sociales y rituales similares. 
Por lo tanto los enterramientos múltiples responden a un concepto distinto al de los colectivos practicados en abrigos naturales, megalitos o incluso grandes fosas utilizados como panteones de uso diferido. Ello justifica las tres diferencias básicas que caracterizan dichos enterramientos múltiples frente a los colectivos: el menor número de individuos que incorporan, el menor tamaño de las cámaras y la ausencia de acceso a las mismas. Pues mientras las tumbas colectivas están diseñadas para poder reabrirse, las múltiples -según se desprende de los casos estudiados en Camino de las Yeseras o Humanejos, están concebidas para ser selladas o protegidas por una cubierta efímera la cual se retira cuando se produce el óbito del último individuo que se tenía previsto inhumar. Esta práctica facilita la conservación de los cuerpos en conexión anatómica al producirse las esqueletizaciones en un ambiente colmatado y permite profundizar en la lectura tafonómica.

Estas consideraciones nos han motivado a presentar este estudio en un intento de avalar la simultaneidad de los enterramientos y lo que es más interesante, comprobar que de manera excepcional se llevaban a cabo recolocaciones de algunos individuos en un lapso temporal muy próximo al de los depósitos primarios. Todo ello, en un intento de crear una particular y probablemente emotiva escenografía avalada por las observaciones tafonómicas.

\section{EL ENTERRAMIENTO DE LA ESTRUCTURA 1461}

\subsection{Material y Métodos}

El trabajo se inscribe en el marco de las investigaciones llevadas a cabo en dos de los poblados calcolíticos madrileños recientemente excavados (Liesau et al., 2008 Blasco et al., 2009; Blasco et al., 2011 y Flores, 2011) las cuales han permitido documentar siete de estos enterramientos múltiples, tres de ellos en Humanejos y cuatro en Camino de las Yeseras, un número que resulta excepcionalmente importante en proporción al total de las tumbas de este tipo de cronología calcolítica conocidas en el centro peninsular.

En este estudio queremos presentar una tumba localizada en Humanejos (Parla, Madrid) (Figura 1a). Se trata de uno de los ejemplos de mayor complejidad y mejor conservados. Es un yacimiento de prolongada ocupación a lo largo de las diferentes etapas de la Prehistoria Reciente y la Historia Antigua y Medieval, con especial continuidad en el III y II milenios a.C. y que todavía hoy se encuentra en proceso de estudio. En él se han documentado 2176 subestructuras: hoyos, zanjas y recintos, de las que 1500 son calcolíticas (Flores, 2011: 13). Corresponden a áreas de función tanto residencial y productiva, como a uso funerario, el cual está avalado por un registro de 50 fosas de enterramiento calcolíticas (Figura 1b).
Para la descriptiva de los ocho cuerpos recuperados en esta fosa hemos adoptado una numeración que se corresponde con el orden establecido en el proceso de inhumación, según se explica más adelante en el estudio tafonómico. En el estudio antropológico, las descripciones, medidas e índices han seguido las técnicas descritas por Knussmann (1986), Martin y Saller (1957), Ferembach (1974), Olivier y Demoulin (1984). La estimación de la edad se ha realizado a partir del grado de erupción dentaria de Ubelaker (1989) y por el grado de desarrollo de los huesos (Scheuer y Black, 2000) en individuos no adultos, y por las fases en la sínfisis púbica descritas por Todd (1920) y los cambios en la metamorfosis del extremo esternal de la cuarta costilla en Iscan et al. (1987) y Ubelaker (1989). La estatura se ha estimado a través de las ecuaciones de Mendonça (2000). El estudio antropológico ha sido realizado por Gómez y Grueso (informe inédito) del que se presenta una síntesis.

\subsection{La tumba y la población inhumada}

La tumba se encuentra integrada en un poblado de campo de hoyos, todavía en fase de estudio por sus excavadores y del que, de momento, no se pueden ofrecer más detalles en relación con las estructuras del entorno al estar en fase de estudio (Figura 1b). La fosa tiene sección cilíndrica con un diámetro de 2,50 metros y una profundidad de 0,60 metros. En ella no ha sido posible reconocer ningún tipo de revestimiento ni de aislamiento o preparación previa en paredes o suelo (Figura 2a).

En relación con los enterramientos, presenta la particularidad de tener dos niveles estratigráficos bien diferenciados: el superior, muy alterado, en el que se inhumaron dos individuos jóvenes, ambos de sexo indeterminado debido a su mal estado de conservación, y el inferior con seis inhumaciones: dos adultos que se han podido sexar como varón y mujer, un juvenil y tres infantiles (Figura 2 a y b), cuyas edades, como veremos a continuación, se ajustan a lo que podría ser una familia nuclear, si bien no disponemos de análisis de ADN que lo certifique.

Afortunadamente los cuerpos del nivel inferior presentan un estado de conservación aceptable que nos ha permitido inferir bastantes datos (Figura 2 a). Todos ellos se encontraban depositados directamente sobre la base de la fosa cuyo considerable tamaño responde a la necesidad de alojar, de manera conjunta, a un número de individuos tan importante $\mathrm{y}$, posiblemente también, porque se preveía una disposición más o menos diferenciada de alguno de los componentes del grupo, cuyas características describimos a continuación siguiendo el orden o sucesión secuencial de las inhumaciones.

-Individuo $\mathrm{n}^{\circ} 1$ (Figura $2 \mathrm{~b}, \mathrm{n}^{\circ} 1$ ), se trata de un infantil de entre 10 y 11 años, a partir de la erupción dentaria y de las medidas de los huesos largos. Por la 

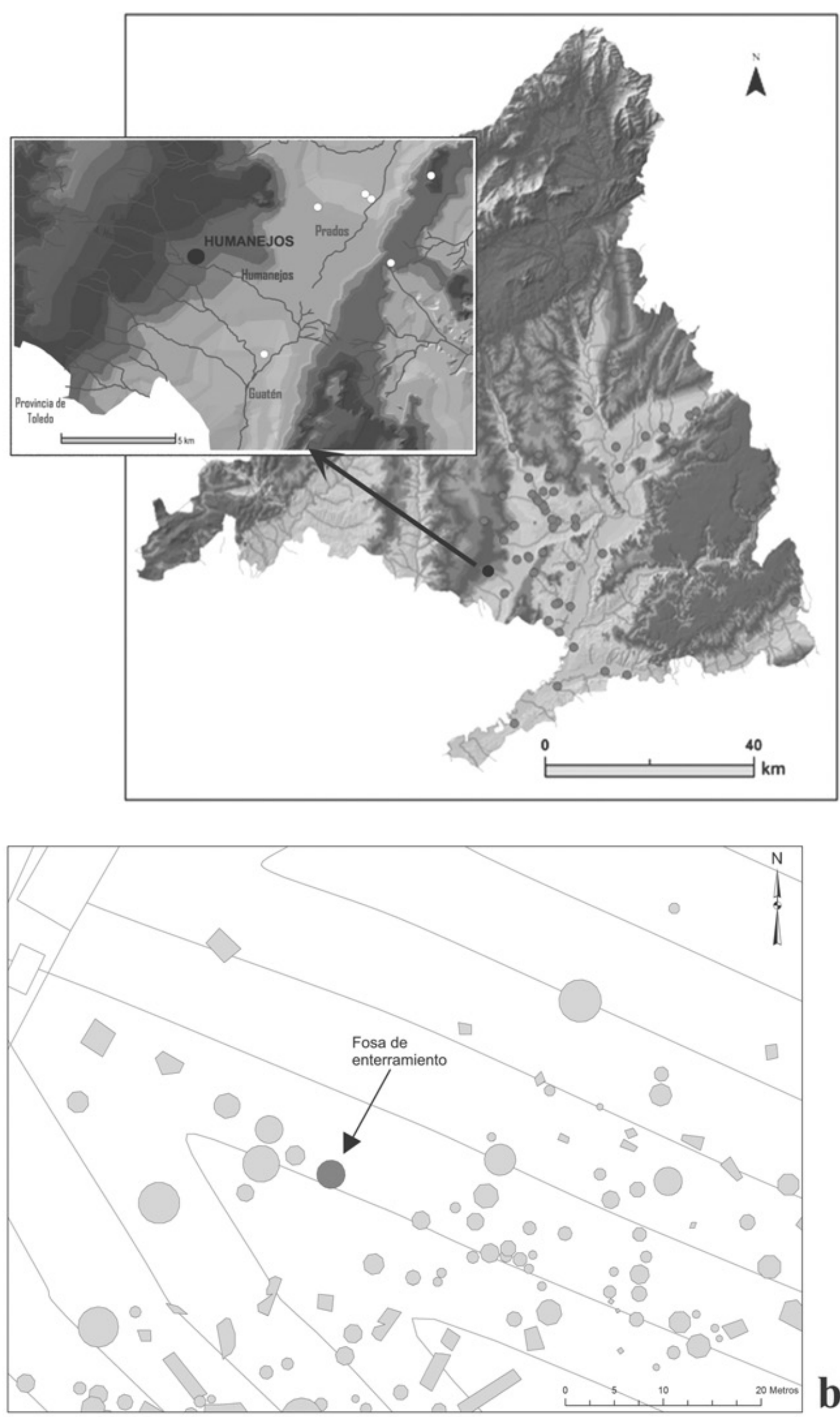

b

Figura 1: a) Situación del yacimiento calcolítico de Humanejos al suroeste de la región en el actual municipio de Parla (Madrid); b) Detalle de la planimetría del yacimiento sobre el área en la que se localizó el enterramiento con indicación de la fosa. 
morfología de los coxales podría tratarse de un varón de cuyos restos no se han podido obtener más datos.

-Individuo $\mathrm{n}^{\circ} 2$ (Figura 2 b, $\mathrm{n}^{\circ} 2$ ). Corresponde a un juvenil con una edad estimada entre los 13 y los 15 años, más cerca del primero que del segundo. Es de sexo femenino, a partir de los caracteres específicos observados tanto en la pelvis como en el cráneo. Su estatura, a juzgar por la longitud del fémur, rondaría los $150 \mathrm{~cm}$. Presenta carillas de acuclillamiento en sus tibias que pudieron deberse a una causa postural habitual.

Las hipoplasias dentarias se limitan a no más de dos sucesos distintos. Se trata de un defecto en la formación del esmalte que se manifiesta con unas líneas transversales en la superficie dentaria. Suele estar asociado a períodos de estrés durante la formación de los dientes, bien por episodios infectocontagiosos $\mathrm{O}$ carencias nutricionales (Goodman et al., 1980).

-Individuo $\mathrm{n}^{\circ} 3$ (Figura 2 b, n 3 a y b y Figura 6 derecha) Se identifica con un infantil cuyos caracteres sexuales secundarios parecen indicar que estamos ante un varón. Por el grado de erupción dentaria la edad estimada es de unos 11 años \pm 30 meses $\mathrm{Al}$ igual que el individuo $\mathrm{n}^{\circ}$ 5 , en casi todas las piezas dentarias se observan hipoplasias del esmalte que se corresponden con, al menos, 4 episodios diferentes de estrés.

A diferencia de la determinación de la edad por el estudio dental el esqueleto postcraneal presenta un desarrollo tan escaso que equivale al de un individuo de entre 5 y 7 años. Dado que la erupción dentaria prima sobre el desarrollo óseo a la hora de establecer la edad del individuo, se infiere una anormalidad en el proceso de crecimiento del niño. No sabemos si esta anomalía pudo estar relacionada con los procesos causantes de las hipoplasias del esmalte antes citadas, o por otros problemas cuyas causas no se detectan.

Sus restos se encuentran localizados en dos puntos distintos de la fosa. Por una parte, el coxal, el antebrazo y mano derechos y los miembros inferiores se encuentran sobre los cuerpos de los individuos 1-2 y bajo los del individuo $4 \mathrm{y}$, por otra, el tronco, el brazo derecho y parte del izquierdo brazo están colocados junto al individuo 5. En ambos casos, en perfecta conexión anatómica.
-Individuo $n^{\circ} 4$ (Figura 2, $n^{\circ} 4$ ) Se trata de una mujer adulta que tenía una edad entre los 26 y 30 años estimada a partir de la morfología de la superficie de la sínfisis púbica y la fusión de los anillos cartilaginosos de los cuerpos vertebrales recuperados. También se ha calculado su estatura en 155,03 $\pm 6,9 \mathrm{~cm}$. a partir de la longitud del fémur.

Poseía una potente musculatura superior según lo atestiguan las inserciones musculares de los huesos del tórax y de los brazos. En cambio, este desarrollo muscular no se aprecia en las extremidades inferiores, por lo que podemos presuponer que habitualmente tenía una importante actividad con los brazos, mientras que las piernas no intervenían en ella de una manera regular.

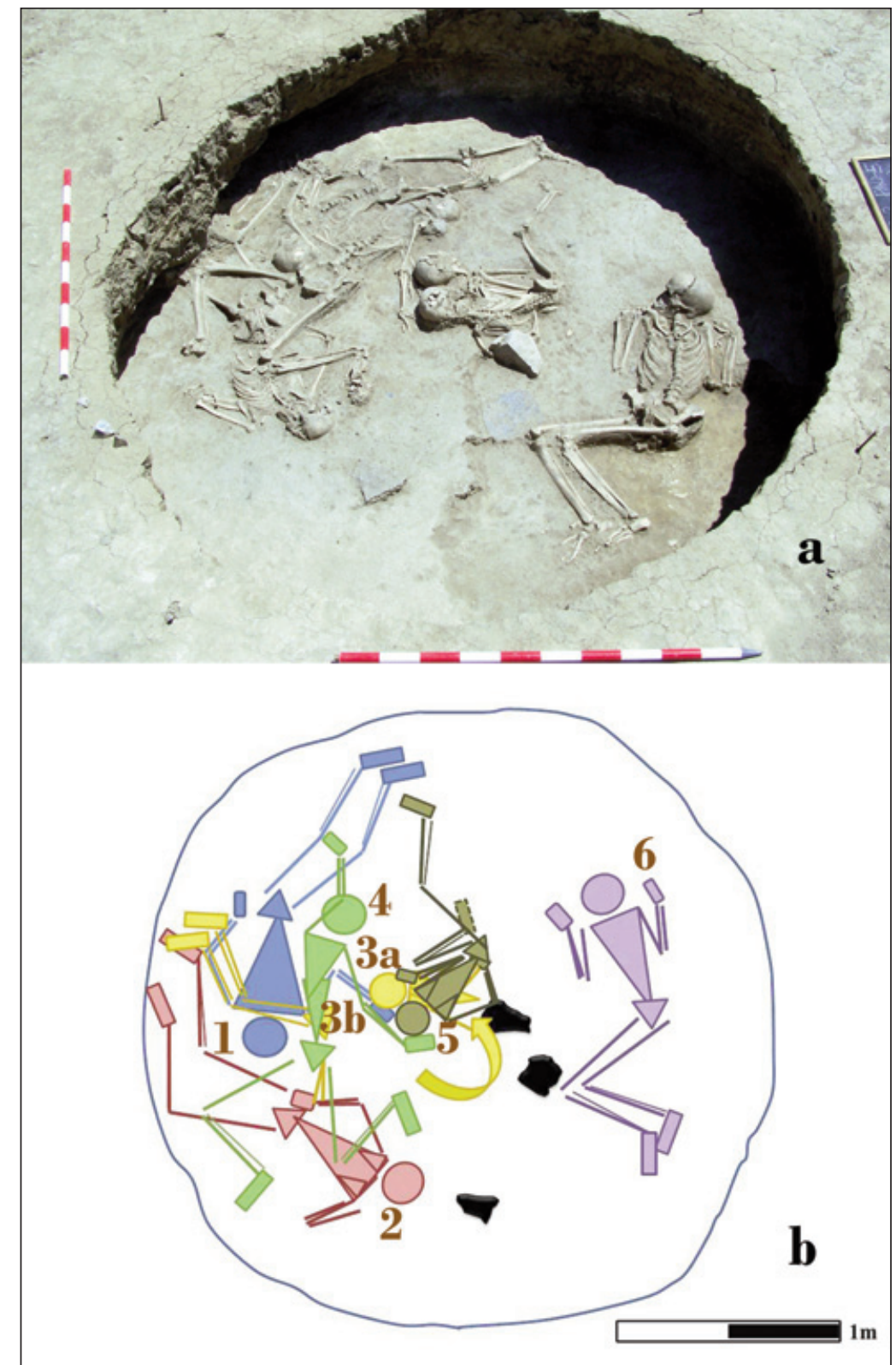

Figura 2: a) Vista general de la tumba con seis inhumaciones del nivel inferior. Destaca el amontonamiento de cinco cuerpos a la izquierda frente al esqueleto del varón adulto mirando hacia el grupo. b) Esquema de la posición adoptada por los cuerpos en el proceso de inhumación. 
Este tipo de actividades es propia de la molienda o de cualquier otra función cotidiana realizada en cuclillas o semiarrodillada. Eso justificaría también los rebordes óseos que se aprecian en los procesos articulares de las vértebras lumbares y las modificaciones degenerativas de las carillas costales de las vértebras torácicas. Además presenta el tercer dedo del pie derecho deformado por alguna lesión antigua.

Esta mujer conservaba la totalidad de las piezas dentarias excepto dos incisivos laterales, uno superior y otro inferior. Todas ellas presentan poco sarro y su desgaste es de grado medio, normal para su edad y época. También se han observado exfoliaciones en premolares y molares, indicativas de una dieta con un elevado contenido en partículas duras, que pueden desprenderse por el uso de los molinos de granito o a causa de su mezcla con otros alimentos de origen vegetal.

-Individuo $\mathrm{n}^{\mathrm{o}} 5$ (Figura 2 b, n ${ }^{\mathrm{o}} 5$ y Figura 6 izquierda, esqueleto completo). Es un infantil que tenía una edad inferior a los 12 años por la ausencia de fusión en huesos largos y de la pelvis, y la erupción dentaria.

En casi todas las piezas dentarias se observan hipoplasias lineales del esmalte que se asocian, al menos, a cuatro episodios de estrés diferentes, como consecuencia de infecciones prolongadas, problemas nutricionales, etc. (Figura 4).

-Individuo $\mathrm{n}^{\circ} 6$ (Figura 2a lado derecho y Figura 2 $\mathrm{b}^{\circ}{ }^{\circ}$ ). Es un varón adulto, con una edad entre los 27 y los 30 años. También se ha estimado su altura, entre 154,6 y $164,8 \mathrm{~cm}$, con un valor promedio de $159,5 \mathrm{~cm}$. en función de las longitudes de los huesos largos de la extremidad superior y utilizando diversas ecuaciones de regresión.

Durante la infancia, según se desprende por la total cicatrización de la cortical craneal, sufrió un traumatismo que le provocó un arrancamiento parcial del cuero cabelludo. Dicha lesión llegó a afectar hasta la región media del cráneo donde se perforó fracturándose la bóveda craneana de lado a lado (Figuras 3 a y Figura 3b, línea curva inferior). La fractura pudo producirse bien por un golpe directo con un objeto plano y con un extremo agudo o bien por una caída accidental sobre una superficie de las características mencionadas. Por otra parte, en sus piezas dentarias se han encontrado varias hipoplasias del esmalte que reflejan diversos momentos de estrés en los primeros años de vida. Uno de ellos podría estar relacionado con el mencionado traumatismo craneal y otro posiblemente con el destete (Hutchinson y Spencer 1988).

En el postcraneal hay más información sobre su vida. Las clavículas muestran una faceta articular acromial pulida con una cortical muy delgada y con mucha porosidad, estando más marcada la del lado derecho (Figura 3c).
En lo que se ha podido recuperar de las escápulas, sus cavidades glenoideas están modificadas, la derecha con un reborde muy pronunciado y la izquierda con los bordes algo pulidos. Todo ello indica que tuvo un importante, y quizás constante, ejercicio físico que, de manera bastante reiterada, involucraba a ambos brazos, movimiento reflejado también en las modificaciones óseas de sus clavículas y escápulas, así como por las poderosas inserciones musculares de los huesos de brazos y manos, que han desarrollado rebordes y espículas (espinas óseas).

A juzgar por las cadenas musculares que parecen intervenir, es posible que se tratara de movimientos amplios relacionados con la carga y empuje de objetos pesados en los que se utilizaban activamente las manos, realizando la acción de sujetar algo con fuerza. Una mayor reacción ósea de la mano derecha puede indicar que probablemente estemos ante un individuo diestro.

En las extremidades inferiores hay una artropatía en la articulación coxofemoral, degeneración poco habitual en un individuo joven, la cual se suma a las entesopatías y a los diversos rebordes óseos hallados en los huesos largos. También presenta una entesopatía del ligamento plantar del pie derecho, comúnmente conocido como espolón (Figura 3d). Estas evidencias permiten señalar que la actividad realizada por este sujeto también involucraba a la parte inferior del cuerpo, intuyendo que hacía fuerza con la pierna izquierda flexionada y la derecha estirada. En consecuencia, una actividad así debería de haber afectado también a la columna vertebral. En efecto, al revisar los fragmentos vertebrales hallamos varias vértebras lumbares con exóstosis y osteofitos de gran tamaño que muestran una reacción ósea atribuible a una respuesta mecánica ante una sobrecarga de las mismas.

El nivel superior de la fosa, al ser muy superficial, ha perdido la mayor parte de la información que podía haber ofrecido su contenido y tan solo podemos decir que se han recuperado unos pocos restos de dos individuos, aunque en ellos están presentes prácticamente casi todas porciones esqueléticas. Ambos cuerpos fueron alojados cuando ya estaba sellado el nivel inferior de la fosa.

-El individuo $\mathrm{n}^{\circ} 7$, el más completo, era un joven de una edad de en torno a los 20 años con una estatura de unos $149 \mathrm{~cm}$. Presenta cuatro episodios de hipoplasia del esmalte en los caninos. Uno de ellos muestra una caries y un desgaste anómalo, no atribuible a la masticación.

- Del individuo $\mathrm{n}^{\circ} 8$ tan solo sabemos que tenía una edad de unos 18 años. Algunas de sus piezas dentarias, muestran tan solo una línea de hipoplasia. Las edades de ambos individuos no parecen encajar directamente en el posible grupo familiar del nivel inferior. 


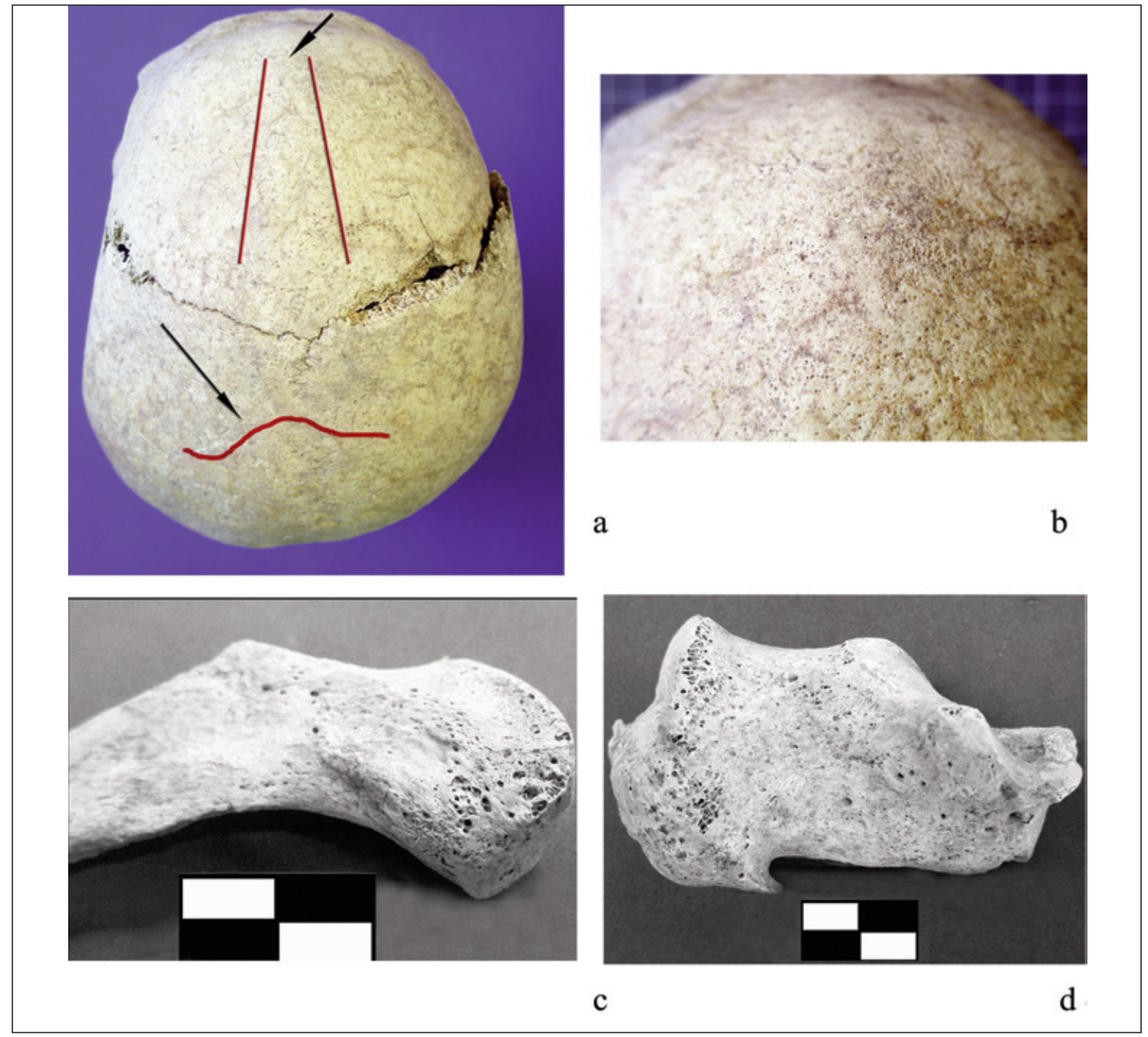

Figura 3: Detalle de algunas patologías del varón adulto (individuo 6).

a) Norma superior del cráneo en donde se aprecian las lesiones. Las líneas rectas marcan el surco producido por el arrancamiento del cuero cabelludo y la línea inferior irregular perfila la cicatriz dejada por la fractura ósea; b) Detalle de la cortical en la zona escalpelada; c) Faceta articular acromial pulida con la cortical adelgazada y su porosidad y

d) Entesopatía del ligamento plantar (espolón).

\subsection{El ritual de inhumación a través de la} Tafonomía (Figura 5)

Son muchos los datos que puede aportar el estudio de una tumba desde una aproximación tafonómica y ofrecer propuestas de cuáles son las posibles causas que expliquen las posturas forzadas que adoptan algunos de los cuerpos. Entre ellas, barajamos como posible, la existencia de un eje central para la sustentación de una posible cubierta efímera instalada inicialmente, hasta el sellado definitivo de la fosa. Esta observación ya es antigua, como se explicó para el túmulo de la Atalayuela, donde se habla de la presencia de un poste central para la sustentación de una superestructura construida "sobre la superficie del suelo, con puntales más endebles y ligeros contorneando la fosa y conflu-

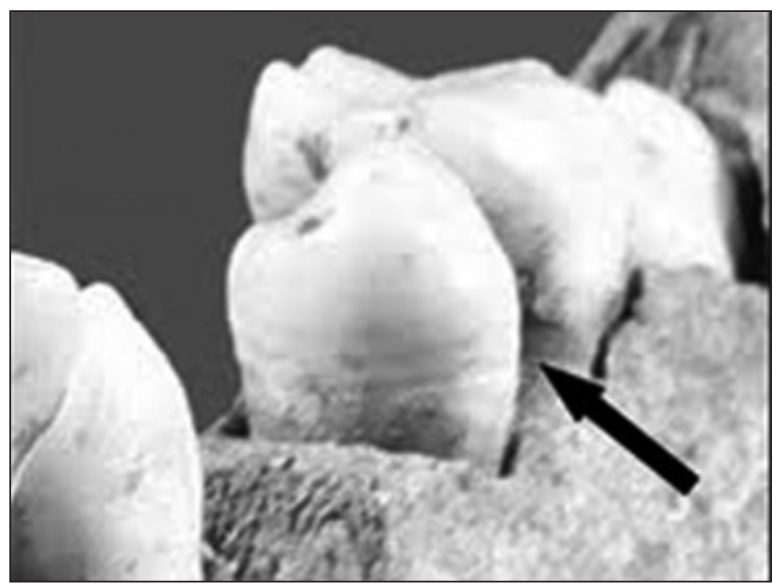

Figura 4: Detalle de las estrías de los episodios de hipoplasia del individuo 3. 

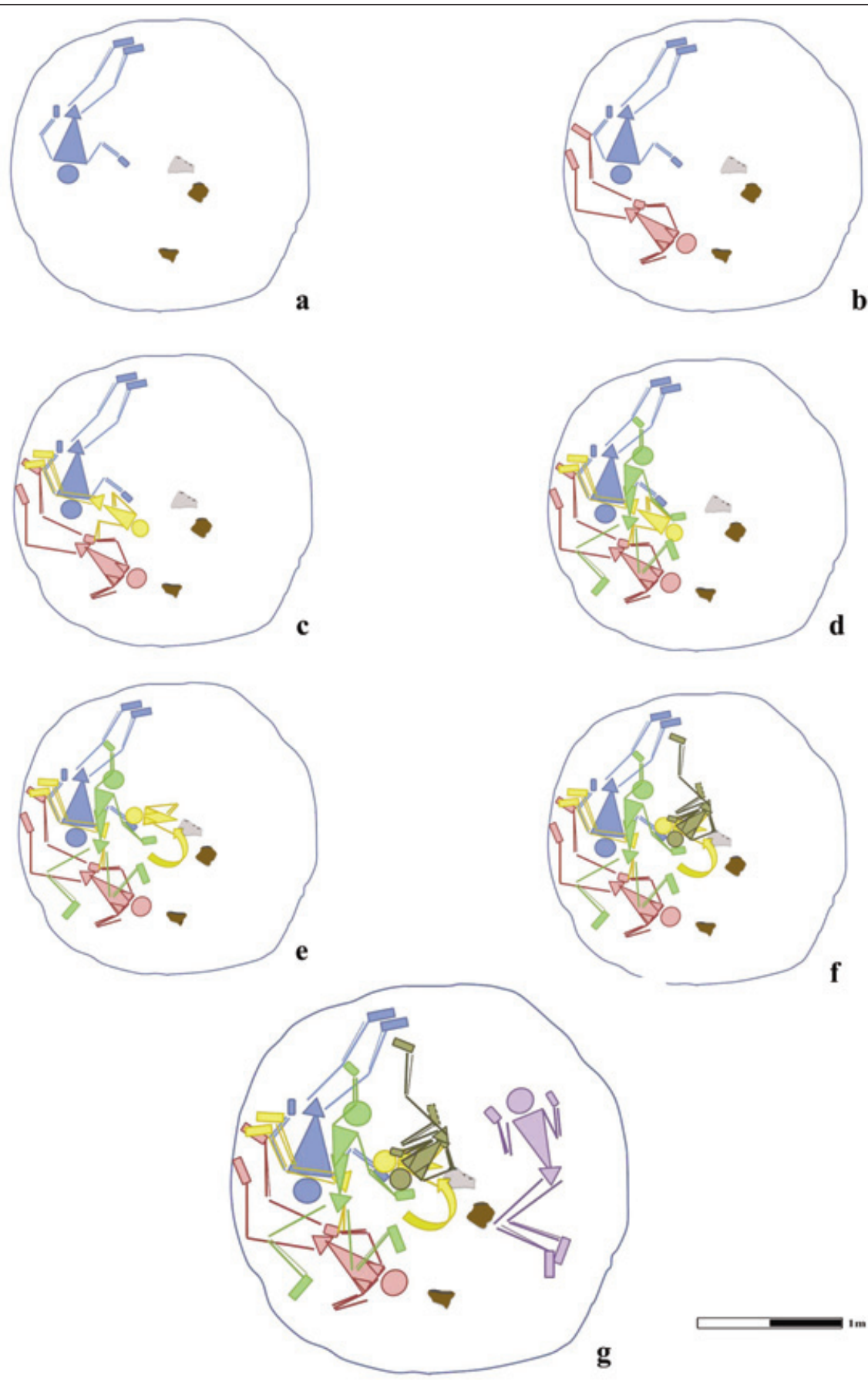

Figura 5: Siguiendo criterios tafonómicos, secuencia de inhumación de los diferentes individuos $(\mathrm{a}-\mathrm{g})$ y desplazamiento del individuo $\mathrm{n}^{\circ} 3$ para colocarlo, aunque sólo de forma parcial, junto al individuo 5 (e).

yendo hacia el pilar central a modo de techado de cabaña, conjunto seguramente retirado cuando se efectuó el enterramiento de las víctimas de la matanza, en la tumba definitivamente clausurada por el túmulo" (Andrés y Barandiarán, 2004: 106). También esta probabilidad ha sido barajada este tipo de estructura en una de las fosas colectivas de Camino de las Yeseras (Gómez y Aliaga, 2010: Figura 2).

Otra hipótesis no descartable es que dicho elemento vertical formara parte de una separación que, a modo de biombo o paraviento, sirviera de división interna del área funeraria, aspecto que, además, explicaría la diferente ocupación del espacio, con la intención de destacar a unos determinados individuos, concretamente en nuestro caso al varón adulto y dos infantiles. La presencia de elementos divisorios efímeros en el interior de las tumbas múltiples y colectivas no son una novedad ya que están documentadas en el Área Funeraria 3 (Cabaña 5) de Camino de las Yeseras con una doble hilera de hoyos de poste que parecía indicar 
una separación y/o cobertura del espacio funerario (Blasco et alii., 2005: 459). Una explicación similar se ha inferido en otras cámaras funerarias con enterramientos colectivos, como el túmulo del Castillejo en Huecas (Toledo) (Bueno et al., 2010: 174).

Otra posibilidad es que hubiera tenido la función de hito señalizador de la tumba con el fin de facilitar su localización en el interior de un gran centro con usos diversos distinguiéndola de las de su entorno y recordando su inviolabilidad y su obligado respeto y consideración. De hecho, la señalización de tumbas monumentales o no, es un fenómeno bastante generalizado sobre el que algunos autores han llamado la atención, aunque generalmente refiriéndose a espacios abiertos, exentos de otras arquitecturas, al considerarlos "construcciones perdurables y visibles" (Andrés, 1998:145). Sin embargo, poco se ha dicho de los posibles indicadores de este tipo de tumbas en fosa, localizadas en un entorno de constante tránsito con subestructuras cercanas utilizadas en actividades diversas y sometidas a un mayor riesgo de alteración y por tanto su señalización sería más que necesaria para garantizar su perdurabilidad.

Dada la posición de los esqueletos podemos establecer que esqueletizaron en un espacio colmatado. Es decir, que se produjo un efecto pared provocado por la tierra en torno a los cuerpos manteniéndolos en la misma posición en la que fueron depositados ya que los huesos no tuvieron espacio para moverse por acción de la gravedad a medida que los ligamentos que los mantenían unidos fueron descomponiéndose. Incluso las articulaciones lábiles de huesos pequeños, con muy pocos ligamentos y escasa masa muscular, tales como las falanges de manos y pies, que son las primeras en luxarse, mantuvieron su posición anatómica original (Duday, 1997; Duday y Guillon, 2006).

Sólo las costillas de todos los individuos mostraban un ligero desplazamiento hacia el interior del tórax, un proceso que se produce por la creación de un espacio vacío secundario como consecuencia de la descomposición de las vísceras en el interior del abdomen y de la caja torácica. Estas observaciones son por tanto, datos muy significativos para poder diagnosticar que nos encontramos ante un caso claro y excepcional de enterramiento múltiple y por tanto simultáneo de seis individuos cuya muerte debió de suponer un episodio singular dentro de su comunidad.

Evidentemente, desconocemos si cada cuerpo fue inhumado en una ceremonia distinta o, por el contrario, dos o más de ellos se inhumaron en un acto conjunto. Las posiciones de los cuerpos indican que no todos fueron inhumados de igual manera. Así, mientras los primeros presentan los pies junto al borde de la fosa $y$ el resto del cuerpo extendido superponiéndose unos a otros, debido seguramente a que fueron arrojados desde el borde de la fosa sin que el o los enterradores llegaran a pisar en el interior, los últimos, están aleja- dos del borde presentan posición más cuidada en decúbito prono-lateral o lateral con las extremidades ligeramente flexionadas evidenciando que fueron colocados accediendo el portador del cuerpo hasta el interior de la tumba para depositarlo.

El estudio tafonómico también revela que la forma de sujetar el cadáver tampoco fue igual en todos los casos ya que mientras los tres primeros en ser depositados fueron transportados sujetos exclusivamente por las axilas, en cuyo caso se dejaron caer apoyando en primer lugar los pies y después el resto del cuerpo, los tres restantes fueron llevados en brazos soportando el peso del cuerpo en la parte posterior de las rodillas y el cuello lo que permitió colocar los cuerpos con más cuidado.

Al darse la circunstancia de que cuatro de los seis cuerpos se colocaron parcialmente superpuestos, hemos podido determinar la secuencia del depósito (Figuras 2b y 5). Concretamente la primera inhumación fue la de uno de los varones infantiles (individuo 1) cuyo cuerpo se trasladó sujeto por debajo de las axilas y se dejó caer apoyando los pies en primer lugar, en la caída el cadáver adoptó una posición forzada, quizás por la presencia del elemento vertical al que hemos hecho referencia, de tal manera que quedó sobreelevado respecto a la pelvis y con los pies orientados hacia el sur y la cabeza girada hacia el norte (Figura 5a).

A continuación se depositó el cuerpo de la mujer joven, (Individuo 2); el cadáver debió de ser traslado de manera similar al anterior y fue arrojado desde el norte de la fosa, colocando los pies orientados hacia el perfil de la misma y dejándolo caer hacia la derecha sin conectar con el individuo anterior. A diferencia del primero, quedó en posición de decúbito prono, con las manos bajo el cuerpo, la izquierda bajo la pelvis y la derecha bajo el hombro de ese mismo lado (Figura 5b).

El tercer individuo en ser introducido fue otro infantil (individuo 3). El hecho de hacerlo desde el mismo sitio que el anterior produjo un amontonamiento para el que no hay una justificación aparente, ya que la fosa era lo suficientemente amplia como para respetar un espacio para cada cuerpo. Es posible que, además de haber algún impedimento físico (un posible poste leñoso al que hemos hecho referencia), existiera una razón ritual que desconocemos. Este cuerpo fue transportado de igual forma que los dos anteriores y quedó con los pies orientados hacia el perímetro de la fosa, es decir de espaldas al centro. Al dejarse caer sobre el tórax del primer individuo inhumado, el brazo izquierdo quedó parcialmente extendido y con la mano contactando con la pelvis del cuerpo infrapuesto, en una posición casi en paralelo al individuo 2 (Figura 5c).

Inmediatamente después o en un lapso temporal próximo, se arrojó el cuerpo de la mujer adulta, (individuo 4). Este cuerpo fue transportado también por un solo individuo pero, en este caso, sujetándolo por 
debajo de las axilas y por las corvas de las rodillas. Al lanzarlo sobre el resto de los cuerpos probablemente provocó su deslizamiento sobre los dos enterrados en primer lugar quedando el brazo derecho extendido sobre la cabeza y el izquierdo separado del cuerpo (Figura 5d).

Desconocemos si todas estas inhumaciones se produjeron en un solo acto o en momentos distintos, pero parece claro que entre la primera y la última inhumación no transcurrió mucho tiempo. Por la posición que adoptan los restos el acto del enterramiento se produjo sin rigor mortis de los cadáveres.

La estratigrafía de la tumba indica que tras la incorporación de todos estos cuerpos, en el espacio de la fosa que había quedado vacío, se realizaron otros dos enterramientos: el de un tercer infantil (individuo 5) y el del varón adulto (individuo 6). Ambas acciones se efectuaron desde el interior de la tumba con el fin de llevar a cabo con más facilidad estos dos últimos enterramientos además de un traslado parcial de restos.

Es probable que en este proceso se desplazara en primer lugar el tronco y parte de los miembros superiores de uno de los niños (individuo 3) excepto el antebrazo que había quedado atrapado bajo la mujer (Figuras 2 b; 6 y 5e), colocándolo boca abajo; destaca que este traslado apenas supuso un recorrido desde su posición primaria de apenas unos centímetros. Cuando se produjo este movimiento posiblemente habría comenzado ya el proceso de esqueletización, pero no debía de estar muy avanzado pues los restos extraídos todavía se mantenían en su emplazamiento, en completa conexión anatómica. Aunque no sabemos si fue necesario realizar algún corte, no se han encontrado huellas de descuartizado, pero teniendo en cuenta su corta edad, la mayor parte de los huesos todavía poseían gran parte de cartílago, lo que habría enmascarado huellas antrópicas de desarticulación en el caso de que se hubieran ejecutado.

Inmediatamente, sobre el mencionado torso se colocó el cuarto individuo infantil (individuo 5) de sexo y edad similar al de los restos desplazados, en su colocación se hicieron coincidir ambos troncos, con la pierna izquierda del esqueleto completo en posición hiperflexionada y el cuerpo en una posición forzada prono-lateral (Figuras 2b, 5f y 6). Se trata de una secuencia compleja y muy meditada que, obviamente, supuso el tránsito por la tumba cuando los primeros inhumados no habían sido todavía cubiertos por sedimento.

No resulta fácil dar una explicación al traslado de sólo una parte del esqueleto de uno de los niños poco tiempo después de haber sido inhumado, con el único fin de arrastrarlo unos centímetros para colocarlo junto al cuerpo de otro infantil de edad similar y en la misma posición.

Posiblemente el último cuerpo introducido fue el del único varón adulto, al que intencionadamente se le quiso dar también un protagonismo diferenciándolo de manera muy evidente del resto al destacarlo en el centro de la zona que había quedado "en reserva" en la mitad sur de la fosa. A diferencia de los individuos restantes, se colocó cuidadosamente en posición de decúbito supino con las piernas flexionadas hacia el interior y los brazos muy doblados en paralelo al tronco y las manos tocando los hombros, de forma muy poco convencional, mientras que la cabeza, estaba girada hacia el Norte y dirigida hacia el resto del grupo (Figura 2 a y 2 b n 6 y Figura $5 \mathrm{~g}$ ). Se trata de una postura intencional tanto en la orientación de la cabeza, como en la colocación de sus miembros la cual solo pudo ser realizada desde el interior de la fosa. No hay duda que el tratamiento dado a este varón es mucho más cuidadoso y minucioso que el otorgado al resto de los componentes del grupo. Tal vez podría ser interpretado como una evidencia de su protagonismo y relevancia con respecto al grupo.

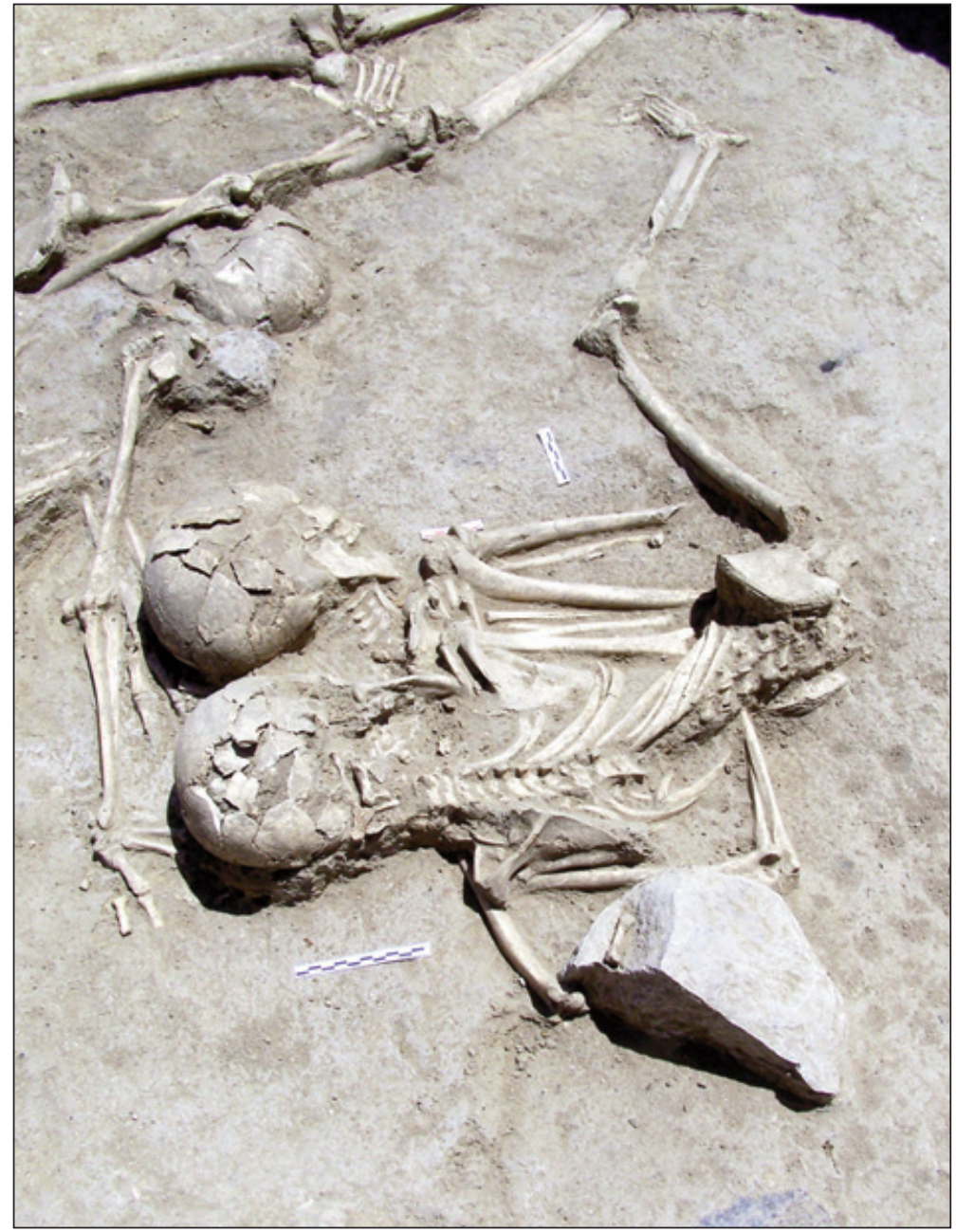

Figura 6: Detalle de la reagrupación de los individuos infantiles 3 y 5 , este último parcialmente colocado sobre el tronco del individuo 3. 
De todo este proceso descrito se deduce que la tumba fue abierta expresamente para la inhumación de un grupo cuyo fallecimiento se produjo en un lapso temporal muy breve y que los cuerpos, una vez depositado todo el grupo, fueron cubiertos por sedimento de manera que esqueletizaron en un ambiente colmatado. Desconocemos, en cambio, el tiempo transcurrido hasta la inhumación de los otros dos cuerpos depositados en el nivel superior, cuya proximidad a la superficie ha provocado la pérdida de parte de los esqueletos impidiendo cualquier observación tafonómica.

\section{4. ¿Ajuar o restos amortizados introducidos accidentalmente?}

Además de los restos óseos humanos se han recuperado algunos fragmentos de cerámica lisa. Es posible que se trate de material intrusivo del sedimento, pero llama la atención que se encuentren bajo las inhumaciones formando parte del lecho sobre el que descansan los cuerpos. El hecho de que sea sólo parte de un vaso invita a pensar que no se trata de un ajuar funerario tradicional como donación a los difuntos, pero no se descarta que nos encontremos ante los restos de una vajilla uti- lizada en alguno de los rituales que pudieron acompañar al sepelio y que se amortizaron como recuerdo de esas exequias.

Más difícil resulta explicar la presencia de un bloque de cuarcita localizado en el centro de la fosa, salvo que se trate de un elemento que junto a otros, posiblemente retirados, se destinó a la sujeción de un cierre provisional, al que ya hemos hecho referencia, que se mantuvo hasta la inhumación del último individuo alojado, momento en que se debió de proceder al desmontaje de una posible cubrición efímera y a la definitiva colmatación (Figuras 2 a centro y 6).

Pero sin duda, lo más conflictivo en contextualizar son una serie de huesos de animales recuperados entre el conjunto funerario (Figura 7). También los 11 restos faunísticos requieren de un estudio tafonómico, muy necesario para su valoración, dado que su estado de conservación, las huellas de origen no antrópico (mordeduras de carnívoros, de roedores o las erosiones radiculares) son determinantes de cara a reconocer la intencionalidad o no de su incorporación a un contexto funerario y sirva de ejemplo esta tumba múltiple de Humanejos.

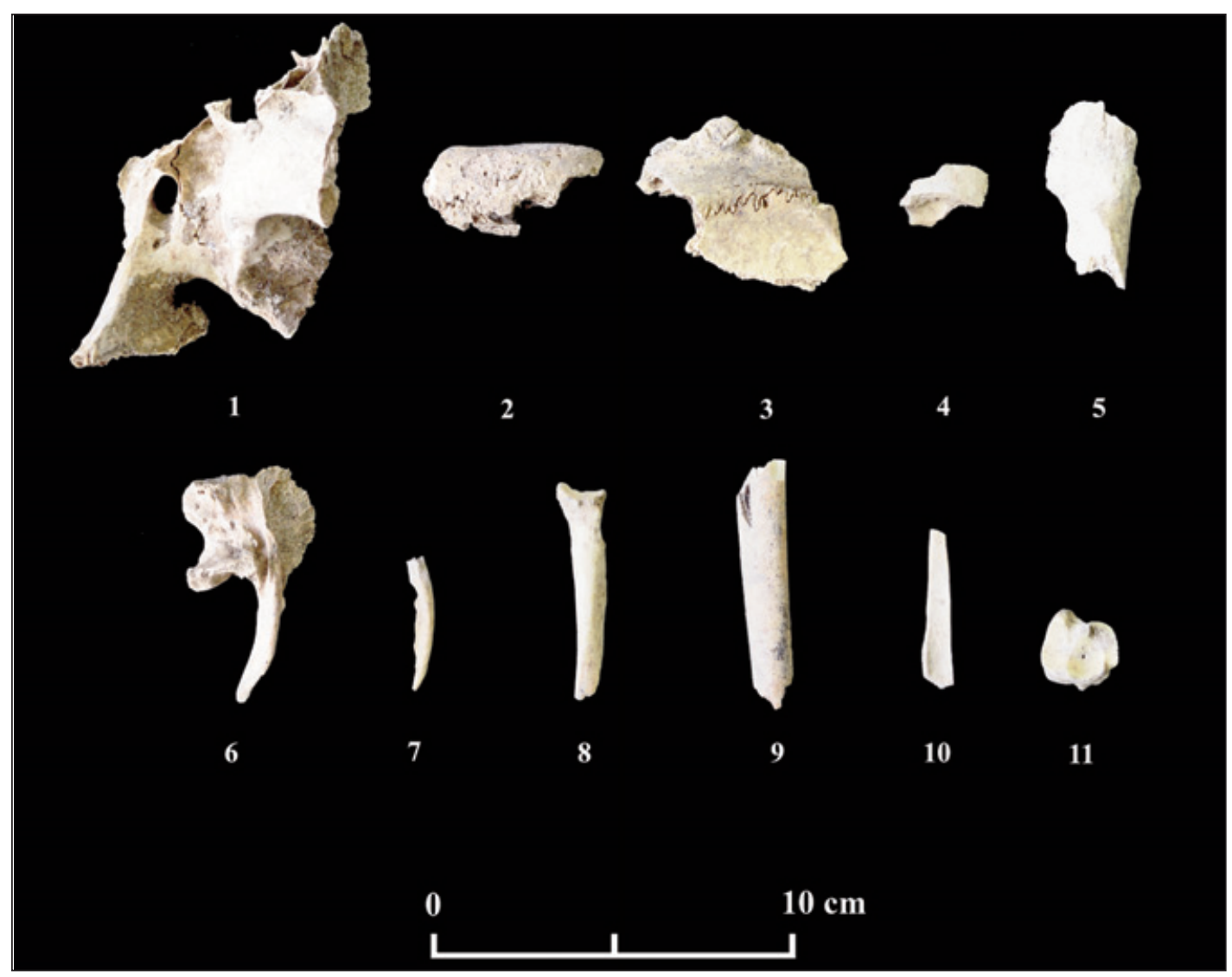

Figura 7: Restos de fauna de la tumba de Humanejos (UE 14611): 1- bovino: cráneo, fragmento de tubérculo articular, norma basal.2.- Bovino: fragmento de occipital, norma dorsal. 3.- Bovino/Cérvido: fragmento de frontal?, norma dorsal, 4.- Ovicaprino, fragmento de frontal con huella de percusión, norma dorsal.5.- Oveja (Ovis aries, L.) esquirla diáfisis de húmero derecha , norma craneal. 6. - cóndilo occipital izquierdo y proceso paracondilar de suido. 7.- Mesomamífero: Fragmento de una lámina costal con mordeduras de carnívoro. 8.- Ovicaprino: fragmento proximal de radio izquierdo con punzaduras de carnívoro en la epífisis. 9.- Ovicaprino: fragmento medial de de diáfisis de metatarso con fractura reciente en la porción proximal y en la distal, donde además presenta huellas de una leve combustión de la pieza.

10.-Mesomamífero: esquirla de diáfisis de hueso largo. Posible pieza de industria ósea, apuntado con fractura reciente en el extremo distal. 11.- Centrotarsal izquierdo de ovicaprino, norma dorsal. 
Como se puede observar en la figura 7, todas las piezas recuperadas son tan sólo fragmentos de diferentes porciones esqueléticas, fundamentalmente craneales y apendiculares de diferentes taxones: bovino, suido, oveja y ovicaprino. Destacan de la muestra varias piezas craneales y una apendicular de bovino (Bos sp.) de posiblemente 2 individuos (Figura 7, 1-3 ) y otro de suido (Sus sp.) con un NMI de 1 individuo (Figura 7,6). El conjunto está también compuesto por un pequeño fragmento craneal y varias esquirlas de diáfisis de oveja y de ovicaprino que también representan a 1 individuo (Figura 7, 4,5, 8-11).

Tan sólo conocemos con mayor detalle la ubicación exacta de la pieza $n^{\circ} 1$ que estaba en contacto directo sobre el pie del individuo 4 (Figura 8) por lo que, en todo caso, sería la única posible donación intencionada. Este fragmento craneal parece corresponder a un bovino de gran talla, mientras que los demás huesos estaban dispersos entre el material de relleno y constituyen un lote de huesos con un acusado grado de fragmentación, además de presentar huellas con mordeduras y punzaduras de carnívoros (Figura $7, n^{\circ} 8$ y 9).

Aun siendo favorable el estado de conservación de los huesos, las características del material desde el punto de vista tafonómico no permiten inferir una intencionalidad como ofrenda funeraria. Si los estudios sedimentológicos no indican lo contrario, parece que la mayoría de estos huesos corresponden a desechos alimentarios del entorno del poblado o del suelo de uso incorporados al sedimento que colmata la fosa.

Aunque los hallazgos de fauna en contextos funerarios calcolíticos no son excepcionales (Fabián 2006 y Lomba et al., 2009), a veces no resulta una tarea sencilla distinguir entre un depósito intencionado de lo que puede ser fauna meramente intrusiva. Evidentemente en aquellos casos en los que se incorporan animales completos o partes articuladas de alguno de ellos, la intencionalidad de los mismos no ofrece lugar a dudas, pero las reutilizaciones de los espacios funerarios -fosas, megalitos, o cámaras hipogeas- causan dificultades para reconocer un patrón característico de taxones o de porciones esqueléticas, especialmente cuando están muy fragmentados y en desconexión anatómica. También son conflictivos los esqueletos de pequeños vertebrados mamíferos, reptiles o anfibios- más o menos completos en función de las técnicas de recuperación (cribado, flotación) o de los lagomorfos o roedores, que por sus hábitos fosores pueden utilizar estos espacios funerarios como madrigueras (Liesau y Schubart, 2006; WeissKrejci, 2006; Liesau, 2012).

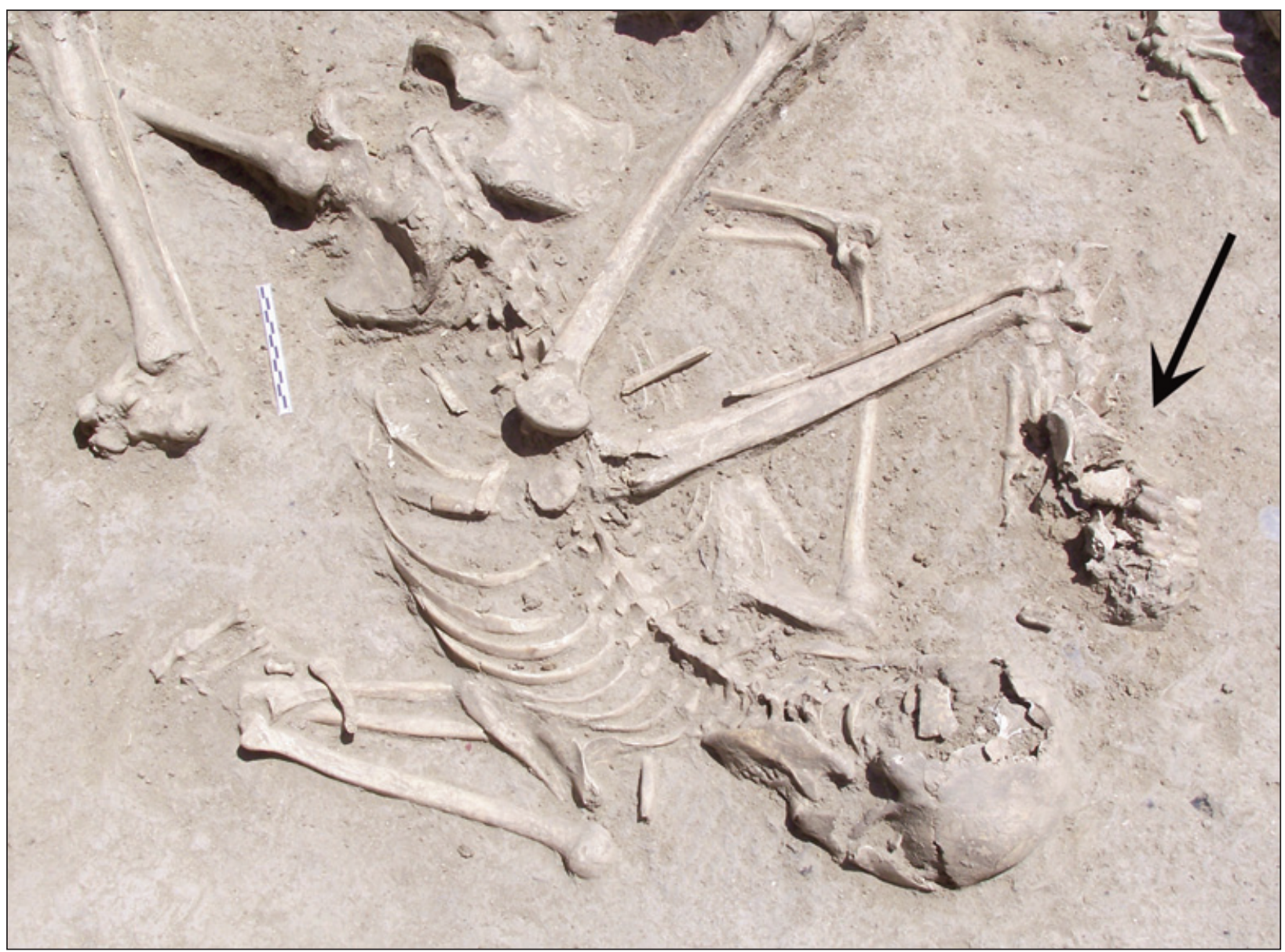

Figura 8: Detalle de restos de cráneo de bovino sobre el pie de la mujer adulta (individuo 4) junto al cráneo de una joven (individuo 2). 
Uno de los casos más llamativos es el hallazgo de unos pocos restos de carnívoros, pero tenemos datos sobre miles de huesos de lagomorfos, con al menos 332 conejos identificados en el espacio funerario del túmulo neolítico de la Velilla (Palencia) y la discusión en torno a la intencionalidad o el carácter intrusivo de dichos hallazgos (Delibes y Zapatero, 1995; Bellver, 2002). Durante las fases avanzadas del Neolítico y el Calcolítico los contextos funerarios con esqueletos completos de animales suelen ser poco frecuentes, mientras que aparecen esporádicamente algunas porciones articuladas de vacuno, ovicaprinos, suidos o cérvidos (Liesau, 2011) y es excepcional la inclusión de ictiofauna (Roselló, 2011). Lo cierto es que si alguno de los restos faunísticos recuperados en esta tumba fuese intencional, se trataría de porciones poco representativas a nivel de ofrenda cárnica.

\subsection{La cronología de los yacimientos con} inhumaciones múltiples en contextos funerarios calcolíticos.

La datación por AMS del individuo infantil 3 ha proporcionado un resultado de 2852-2356 cal B.C. a $2 \sigma(4009 \pm 56 \mathrm{BP})$ una fecha que nos permite situar cronológicamente el enterramiento al menos de los 6 individuos del nivel inferior teniendo en cuenta que el estudio tafonómico no dejar lugar a dudas sobre la rápida secuencia de estas inhumaciones. No obstante, la posibilidad de obtener en el futuro una datación de cada uno de los cuerpos y de someterlas a análisis bayesiano con los datos estratigráficos comentados, podrá confirmar con un intervalo numérico esta circunstancia así como situar de forma más ajustada dentro de la secuencia los restos del nivel superior.

Respecto al momento en que la datación obtenida sitúa el enterramiento en estudio, resulta interesante recordar que se trata de una fecha semejante a las conocidas para otros enterramientos de la región -tanto múltiples como colectivos, localizados en poblados calcolíticos, ya que se centran en torno al 2500 B.C. con una probabilidad que abarca en conjunto desde el 2859 al 2200 a.C. calibradas a dos sigmas (Figura 9). Las 11 fechas disponibles (incluida la de este enterramiento) proceden de 8 tumbas localizadas en 4 yacimientos madrileños diferentes (Ríos 2013).

Se trata de una muestra que creemos, a todas luces insuficiente, pero orientativa para marcar tendencias que habrá que confirmar no sólo multiplicando el número de dataciones y contextos, sino también sometiendo a diferentes análisis estadísticos los intervalos de fechas obtenidos con el objetivo de situar las fases y los cambios entre los diferentes formas de enterramiento en la Prehistoria Reciente madrileña, tal como se ha aplicado para otras zonas (Buck et alii., 1994, 1999; Barceló, 2008; Lull et alii., 2010; Ramsey, 1995). Con ello se cubre uno de los vacíos existentes para conocer las características y evolución de las prácticas funerarias del VI al II milenio a C en el ámbito geográfico que nos ocupa.

Con los datos obtenidos en los yacimientos madrileños estudiados hasta el momento, los enterramientos múltiples se practican a lo largo de casi dos siglos, valga de ejemplo para ambos límites la tumba 1166 del yacimiento de Humanejos y la tumba E02 del Area 85 de Camino de las Yeseras. La primera de ellas es, junto a la que estudiamos una de las más antiguas al haber sido datada en: 2573- 2346 cal BC $(3959 \pm 34 \mathrm{BP})$ coincidente con el tramo más reciente de la tumba estudiada en este trabajo, aunque el ritual de enterramiento es totalmente diferente y no permite discernir si todos ellos se enterraron en un único momento o en actos próximos pero diferenciados (Gómez et al., 2011, 106). El enterramiento del área 85 (El-02) de Camino de las Yeseras, marcaría en cambio, el límite más reciente con una datación 23502190 cal BC (3819 \pm 30 BP). En este caso, su estudio tafonómico ha podido demostrar también la simultaneidad de las inhumaciones de seis mujeres al haber quedado algunos de los cuerpos parcialmente superpuestos (Gómez y Aliaga, 2010; Gómez et al., 2011).

Entre las tumbas colectivas con inhumaciones diacrónicas hemos realizado dos dataciones en dos yacimientos distintos: el denominado túmulo de la parcela T6 de Soto del Henares y una fosa de El Perdido en Torres de la Alameda. El primero de ellos es una fosa con 5 inhumaciones que estaba cubierta por un gran túmulo de piedras, un cierre excepcional entre los enterramientos calcolíticos de esta área geográfica. El análisis por AMS ha proporcionado un valor de 2835-2500 cal BC (4074 \pm 35 BP). La segunda tumba, es una fosa con varias decenas de cuerpos exhumada en Torres de La Alameda, todavía inédita pero de la que hemos obtenido dos dataciones que la sitúan entre 2459-2153 y 2457-2140 cal BC $(3834 \pm 35$ BP y $3816 \pm 40 \mathrm{BP})$, el resultado confirmaría que pese a que el elevado número de inhumaciones es una acumulación de cuerpos producida a lo largo de un lapso temporal limitado, ya que las muestras proceden de dos cuerpos recuperados en la base y en los niveles superiores respectivamente. A la luz de estos resultados, los datos no permiten establecer diferencias cronológicas sustanciales entre los enterramientos colectivos y los múltiples.

Recientemente otros autores se planteaban cuestiones similares a partir del estudio de varios enterramientos en el yacimiento del Cerro de la Cabeza en Ávila, un ámbito donde el registro arqueológico de estos momentos parece similar al del ámbito madrileño (Fabián y Blanco, 2012). Tampoco estos autores encuentran respuestas claras a la interpretación de los enterramientos colectivos y su diversi- 


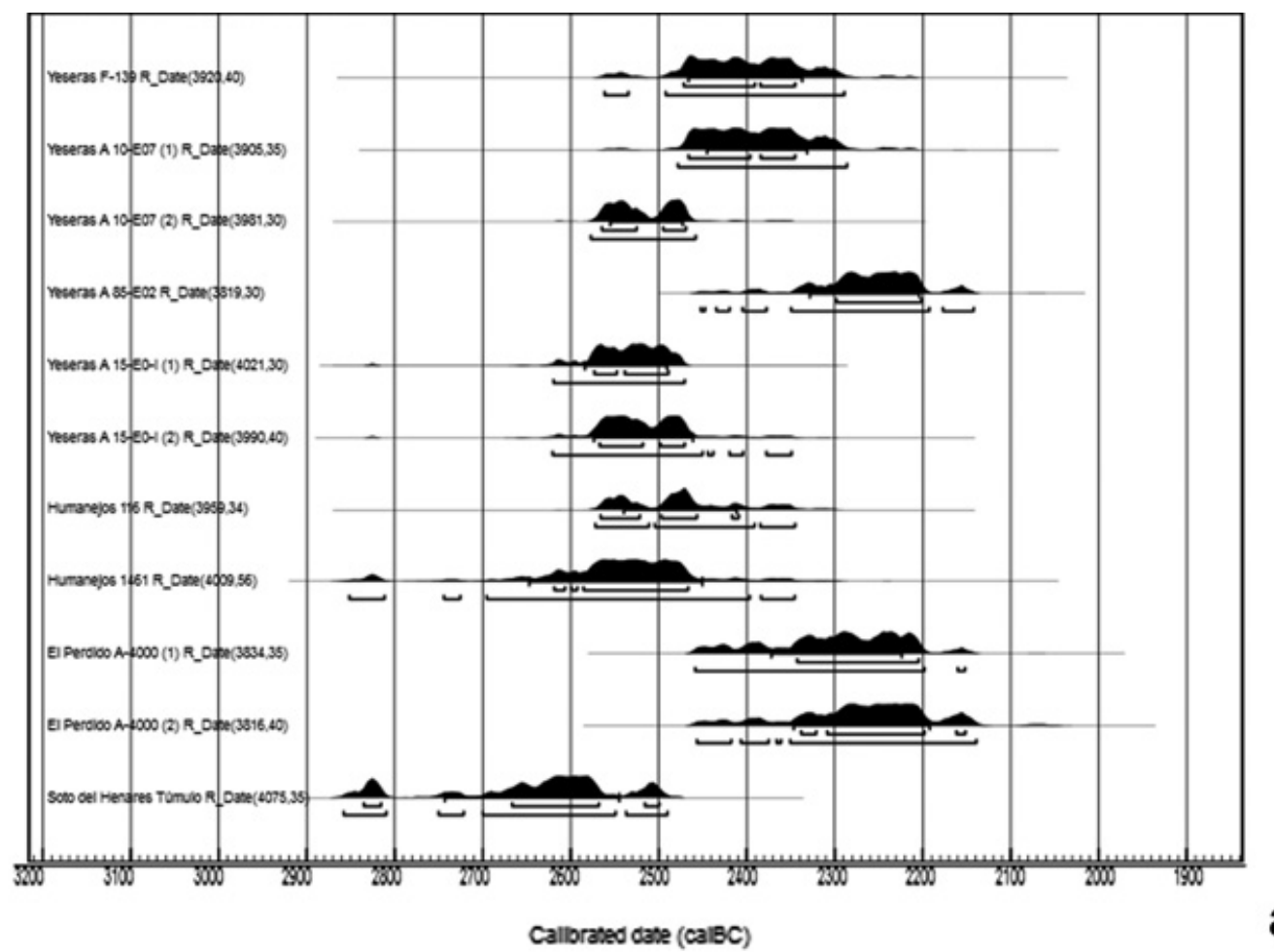

Figura 9: Dataciones de los enterramientos colectivos de la región de Madrid $^{2}$ calibrados con el programa $O x C a l 4.1$ (OxCal v 4.1.7 Bronk Ramsey, 2010; r: 5 Atmospheric data from Reimer et al., 2009): a) gráfico comparativo de las fechas y b) tabla de los intervalos numéricos con diferentes probabilidades.

dad, pero confirman un intervalo cronológico con un límite inferior situado en la fecha comentada del 2200 a C., teniendo como paralelo principal las fechas de Camino de las Yeseras.

A la vista de las dataciones que hemos obtenido, parece que la preocupación por los enterramientos acumulados en una tumba fue perdiendo vigencia, aunque a lo largo de todo el II milenio a.C. siguen siendo numerosos los casos de enterramientos dobles o triples que mantienen el principio de agrupamiento familiar; ya que a partir del 2200 cal a C, tal y como se observa en la figura 9, desaparecerían los enterramientos colectivos en general, reduciéndose, en todo caso a tumbas con dos o tres individuos, y generalizándose los enterramientos individuales atestiguados tanto en Humanejos como sobre todo en Camino de las Yeseras (Ríos, 2011).

Dentro de nuestro proyecto sobre el marco temporal del mundo funerario calcolítico empieza a confirmarse que la irrupción de los primeros campaniformes en los poblados calcolíticos se produce en torno al $2500 \mathrm{cal}$ a. C. con tumbas que parecen mantener un cierto carácter colectivo (Ríos, 2013). Si bien este grupo es más propicio a la práctica de las inhumaciones individuales (Rojo et al. 2005: 239-244).

\begin{tabular}{|c|c|c|c|c|c|c|}
\hline Yacimiento & enterramiento & muestra & ref. Lab. & fecha BP & fecha cal BC $1 \sigma$ & fecha cal BC $2 \sigma$ \\
\hline Camino de las Yeseras & F-139 UE02 & hueso individuo $\mathrm{X}$ & BETA 197527 & $3920 \pm 70$ & $2472-2346$ & $2562-2290$ \\
\hline Camino de las Yeseras & A-10 E07 UE 05 & Individuo 1 & Ua-35013 & $3905 \pm 35$ & $2467-2346$ & $2479-2287$ \\
\hline Camino de las Yeseras & A-10 E07 UE 05 & & Ua-39311 & $3981 \pm 30$ & $2565-2470$ & $2578-2459$ \\
\hline Camino de las Yeseras & A-85 E02 & Individuo 4 & Ua-39312 & $3819 \pm 30$ & $2299-2202$ & $2453-2143$ \\
\hline Camino de las Yeseras & A-15 E01 UE 03 & & Ua-39308 & $4021 \pm 30$ & $2574-2490$ & $2620-2471$ \\
\hline Camino de las Yeseras & A-15 E01 UE 03 & Individuo 4 & Ua-35016 & $3990 \pm 40$ & $2568-2471$ & $2621-2350$ \\
\hline Humanejos & UE-1166/11664 & diáfisis de fémur & Ua-40220 & $3959 \pm 34$ & $2567-2410$ & $2573-2346$ \\
\hline Humanejos & UE-1461/14613 & epífisis de individuo 2 & Ua-41492 & $4009 \pm 56$ & $2619-2467$ & $2852-2346$ \\
\hline El Perdido & $A-4000$ & falange individuo 25 & Ua-41488 & $3834 \pm 35$ & $2343-2205$ & $2459-2153$ \\
\hline El Perdido & A-4000 & falange individuo 4 & Ua-41489 & $3816 \pm 40$ & $2339-2152$ & $2457-2140$ \\
\hline Soto del Henares & Túmulo UE 23524 & mandíbula individuo $\mathrm{x}$ & Ua-43536 & $4075 \pm 35$ & $2836-2500$ & $2859-2491$ \\
\hline
\end{tabular}

Tabla 1. Dataciones realizadas sobre muestras de hueso de enterramientos múltiples madrileños (calibraciones a partir de Oxcal 4.2 IntCal 13).

2 Referencias: Beta 19757- Yeseras F-139; Ua-35013 - Yeseras A 10-E07 (1); Ua-39311 - Yeseras A 10-E07 (2); Ua-39312 Yeseras A 85-E02; Ua-39308 - Yeseras A15-E08-I (1); Ua-35016
- Yeseras A15-E08-I (2); Ua-40221 - Humanejos 116; Ua-41492 - Humanejos 1461; Ua-41488 - El Perdido A-4000 (1); Ua-41489 - El Perdido A-4000 (2); Ua-43536 - Soto del Henares túmulo. 


\section{CONSIDERACIONES FINALES}

En relación con las características de los individuos adultos cabe destacar la existencia de claros marcadores de actividad física, especialmente intensa en todo el cuerpo del varón y en los miembros superiores de la mujer lo que habla de un ejercicio físico diferenciado, consecuencia de unas tareas también distintas. Así mismo es notoria la presencia de hipoplasias dentales en adultos e infantiles que nos indican una población sometida a episodios de estrés, relativamente frecuentes en estas etapas de la Prehistoria.

Los gestos rituales que acompañan a cada una de las inhumaciones reflejan pautas diferenciadas. En cuanto al transporte de los cuerpos destaca la diferente fórmula empleada en adultos y en infantiles, pues mientras éstos son sostenidos exclusivamente por las axilas, los adultos son soportados por las corvas y los hombros, diferencia que podría estar en función del tamaño y envergadura de los fallecidos. Unas circunstancias que también se han podido documentar en otras tumbas tanto de Humanejos como de Camino de las Yeseras.

Sin embargo, es común a todos los cadáveres la ausencia de mortajas y ligaduras con el fin de mantenerlos en una posición prefijada, lo que hubiera facilitado su desvío al ser arrojados a la fosa, ante la presencia de cualquier barrera como sucedió, tanto en ésta como en otras tumbas, por la existencia de elementos verticales que formaron parte de una arquitectura efímera de las cámaras.

Otra explicación parece tener el diferente tratamiento de los cadáveres dentro de la tumba, pues contrasta el especial cuidado que se tiene en la colocación y visibilidad que se da al varón adulto y a dos de los infantiles, frente al amontonamiento y aparente improvisación en el acto de arrojar el cuerpo de la mujer y el resto de los infantiles y adolescentes.

Como se ha visto, la tumba estudiada podría responder por el perfil de los inhumados, a uno de los agrupamientos más característicos: el familiar, incluyendo posiblemente a la totalidad de sus miembros, una hipótesis que, aunque no ha podido ser contrastada por el análisis de ADN, nos parece bastante plausible. Con respecto a las causas que pudieron motivar éste y otros enterramientos conjuntos, opinamos que una primera hipótesis es la eclosión de procesos infecciosos que, en las condiciones de salubridad y escasa disponibilidad de recursos para combatirlos, afectarían con cierta frecuencia y con mayor virulencia a los miembros de la unidad familiar más vulnerables: niños y mujeres en momentos de gestación y lactancia, produciendo sus muertes en lapsos temporales muy próximos y justificando que este tipo de asociaciones sea el más frecuente.

Esta causa explicaría igualmente las numerosas asociaciones de una o dos mujeres con sus respectivos vástagos en una misma tumba, como se ha documenta- do en el propio Yacimiento de Humanejos o en Camino de las Yeseras (Blasco, et al., 2009: 43-44; Vega et al, 2010: 651-652).

No obstante este tipo de asociaciones también se ha interpretado como un argumento de carácter social o ideológico para una de las tumbas del polideportivo de Martos que inicialmente se interpretó como un "enterramiento familiar" donde fueron inhumadas dos mujeres adultas, una de ellas junto a dos infantiles, y la segunda sobre el cuerpo del tercer infantil. En concreto se ha dicho de esta tumba andaluza que "en base a los estudios etnológicos [se justifican porque] ...Los enterramientos femeninos suponen la unión sucesiva de un varón con dos mujeres del mismo linaje con el fin de mantener la propiedad y los hijos fundamentalmente como fuerza de trabajo" (Cámara, 2001: 54), una hipótesis que resulta sugerente aunque difícil de fundamentar a partir de los todavía escasos datos que tenemos sobre la sociedad del III milenio BC en la Península Ibérica.

Pero tampoco se puede descartar una muerte violenta, poco probable en este caso concreto ya que no contamos con ninguna evidencia, ni por lesiones corporales, ni por presencia de posibles armas, de la que existen fundados indicios en otros enterramientos de ésta y otras áreas peninsulares.

Tanto si nos encontramos ante muertes debidas a una causa natural, como a un acto violento no detectable, es poco probable, pero no imposible, que el óbito de todos los miembros del grupo se produjera de manera simultánea, aun cuando hubiera previsión de un desenlace fatal en un corto espacio de tiempo: posiblemente en apenas tres o cuatro días. Pensamos que éste pudo ser el caso de la tumba que estudiamos de manera que los dos individuos que debieron de fallecer después: el varón adulto y uno de los infantiles de unos 10-12 años de edad, se encontraban en una situación terminal que hacía prever su muerte, cuando se realizaron las inhumaciones de los primeros individuos. Por ello, a diferencia de lo que parece que fue habitual, en lugar de colmatar el silo para sellar la tumba, se dejó cubierta con materiales más o menos livianos, posiblemente de naturaleza orgánica, que permitían acceder de nuevo para la incorporación de otros cuerpos. Éste pudo ser también el caso del "enterramiento familiar del Polideportivo de Martos", antes citado, donde, según se indica, el cuerpo de una de las mujeres se depositó en un momento posterior al de las otras cuatro inhumaciones, cayendo sobre los restos de uno de los infantiles y produciendo su desarticulación y desplazamiento (Lizcano et alii,. 1991-92: 41).

La decidida intencionalidad de enterrar unidos a todos los miembros de una determinada comunidad ¿familiar?, incluso cuando las inhumaciones no pudieron realizarse en un mismo acto, resulta especialmente significativa si tenemos en cuenta el escaso porcentaje de individuos que recibieron sepultura convencional. 
Por otra parte la ausencia de ajuares significativos tampoco nos ayuda a identificar el posible significado del grupo o de alguno de sus miembros en su contexto social. ¿Fueron unas circunstancias especialmente dramáticas las que determinaron este ritual? ¿Hubo alguna aportación significativa de este grupo, o de alguno de sus miembros al resto de la comunidad? Por el contrario si queremos ver a través de este ritual el mensaje de la fortaleza del posible vínculo familiar en esta sociedad ¿por qué se trata de casos puntuales que no afectan al resto o, al menos, a la mayoría de las familias?

En cuanto a la disposición final de los cuerpos en la tumba hay que señalar cómo la mujer es colocada encima de dos de los individuos infantiles y del juvenil, quizás en señal de protección. Su depósito pudo haberse realizado en un mismo acto, mientras que tal vez en un segundo momento, se acomodó al varón en un amplio espacio, libre de otros restos, en el extremo opuesto de la fosa y dirigiendo la mirada al lugar donde se encontraban el resto de los cuerpos.

Pero lo más destacable y difícil de interpretar es el especial tratamiento de los restos de un infantil dentro de la propia tumba, pues una vez conseguido este propósito de reunir a todos los miembros del supuesto grupo familiar se fue más allá buscando que dos de los niños, no sólo compartieran una misma tumba, sino que además permanecieran en contacto físico, a pesar de que su muerte acaeciera en dos momentos distintos, pero muy próximos.

Como hemos apuntado más arriba, dada la coincidencia de edad de los dos infantiles, podríamos encontrarnos ante la posibilidad de que fueran ¿gemelos?, para tal hipótesis contamos con un dato que nos indica cierto paralelismo de sus vidas, al menos desde el punto de vista de su historial patológico, ya que ambos muestran las mismas huellas de hipoplasia que señalan haber padecido al menos cuatro episodios de estrés diferentes, dicha coincidencia numérica, podría ser el reflejo de posibles contagios mutuos o de unas circunstancias familiares en pautas de consumo similares. Sin embargo es obvio que no podemos descartar que, por otras circunstancias que se nos escapan, tuvieran una muy especial vinculación lo largo de su corta vida más allá de los lazos de sangre.

Por otra parte no podemos pasar por alto la singularidad de que los restos desplazados pertenecieron a un niño con un insuficiente desarrollo físico, que pudo requerir atención y cuidados especiales por parte del resto de los miembros del grupo y esta circunstancia pudo provocar el deseo de colocarlo en un lugar destacado de la fosa: el mismo centro geométrico y a la vez hacerlo más visible, fuera del amontonamiento de cuerpos, pero destacando sobre todo su vinculación al otro infantil.
¿Se trata en definitiva de reproducir una escenografía que indica de alguna manera el rol tanto de los adultos como el especial significado de alguno de los vástagos?, lo cierto es que la tumba refleja algo más que un deseo muy premeditado de mantener unido al grupo, ya que transmite la idea de evocación de ciertas circunstancias y situaciones que dejaron huella en el grupo: preocupaciones cotidianas, protección, afectos...

\section{Bibliografía}

Aliaga, R. y Megías, M. (2011): Los Berrocales (Madrid): Un yacimiento de la Edad del Bronce en la confluencia Manzanares-Jarama. Patrimono Arqueológico de Madrid 8. UAM y Arqueología Arqueomedia S.L. Madrid.

Andrés, T y Barandiarán, I. (2004): "La tumba calcolítica de la Atalayuela, treinta y cinco años después". Saldvie, 4:85-124.

Andrés, T. (1998): Colectivismo funerario neo-eneolítico. Aproximación metodológica sobre datos de la Cuenca alta y media del Ebro. Institución Fernando el Católitico. Zaragoza.

Barceló, J. A. (2008): "La sequència crono-cultural de la Prehistòria catalana. Anàlisi estadística de las datacions radiomètriques de l'inici de l'Holocè a l'Edat del Ferro", Cypsela, 17: 65-88.

Beguiristain, M ${ }^{\mathrm{a}}$ A., Sesma, J. y García, J. (2011): "Formas funerarias en la Prehistoria Reciente del Pirineo Occidental”. En Fernández Eraso, J. y Mújika, J.A. (eds.), 2011: 226-248.

Bellver, A. (2002): "Comentarios arqueozoológicos al túmulo de "la Velilla" de Osorno en Palencia", España. Akros: 17-21.

Blasco, C., Sánchez Capilla, M ${ }^{\mathrm{a}}$ L., Calle, J., Robles, F., González, V.M. y González, A (1991): "Enterramientos del Horizonte Protocogotas en el Valle del Manzanares". Cuadernos de Prehistoria y Arqueología de la UAM 18: 55-112.

Blasco, C.; Liesau, C.; Delibes, G.; Baquedano, F. y Rodriguez Cifuentes, M. (2005): Enterramientos campaniformes en ambiente doméstico: El yacimiento de Camino de Las Yeseras (San Fernando de Henares, Madrid). En: Rojo, M.; Garrido, R. y García, I. (Coord.): El Campaniforme en la Península Ibérica y su contexto europeo: Universidad de Valladolid y Junta de Castilla León. Serie: Arte y Arqueología, 21. Valladolid:4 57-473.

Blasco, C., Liesau, C. y Ríos, P. (eds.) (2011): Yacimientos calcolíticos con campaniforme en la Región de Madrid. Nuevos estudios. Patrimonio Arqueológico de Madrid, 9 UAM.

Blasco, C., Liesau, C., Ríos, P., Blanco, J. F., Aliaga, R., Moreno, E. y Daza, A. (2009): "Kupferzeitliche Siedlungsbestattungen mit Glockenbecher-und Prestigebeigaben aus dem Grabenwerk von el Camino de las Yeseras (San Fernando de Henares, 
prov. Madrid). Untersuchungen zur Typologie des Grabritus und zu dessen sozialer Symbolik". Madrider Mitteilungen 50, 40-69.

Blasco, C. y Ríos, P. (2005-2006): “Acerca de la diversidad de enterramientos en poblados calcolíticos de estructuras negativas. El ejemplo de Camino de las Yeseras (San Fernando de Henares, Madrid)", Kalathos, 24-25: 105-118.

Bronk Ramsey, C., Dee, M., Lee, S., Nakagawa, T., y Staff, R. (2010). "Developments in the calibration and modelling of radiocarbon dates". Radiocarbon, 52 (3), 953-961.

Buck, C. E.; Christén, J. A. y James, G. N. (1999): "BCal: an on-line Bayesian radiocarbon calibration tool", Internet Archaeology 7. en: http://intarch.ac. uk/journal/issue 7/buck index.html.

Buck, C. E.; Christén, J. A.; Kenworthy, J. B. y Litton, C. D. (1994): "Estimating the duration of archaeological activity using 14C determinations", Oxford Journal of Archaeology, 13 (2): 229-240.

Bueno, P., Barroso, R. y Balbín, R. (2010): "Megalitos en la cuenca interior del Tajo". En. Actas del Congreso Internacional sobre megalitismo y otras manifestaciones funerarias contemporáneas en su contexto social, económico y cultural, Munibe. Suplemento 32: 152-187.

Cámara, J.A. (2001): El ritual funerario en la Prehistoria Reciente en el Sur de la Península Ibérica. BAR International Series 913. Oxford.

Chambon, PH. y Leclerc, J. (2007): “ Les tombes multiples dans le Néolithique français :aléa statistique ou pratique institutionnalisée". Bulletin de la Société préhistorique française, 104,2: 289-306.

Delibes, G. y Zapatero, P. (1995): “De lugar de habitación a sepulcro monumental: una reflexión sobre la trayectoria del yacimiento neolítico de la Velilla, en Osorno (Palencia)". Actas del I Congrés del neolític a la Peninsula Ibèrica. Barcelona: GavaBellaterra

Duday, H. (1997): “Antropología biológica “de campo", tafonomía y arqueología de la muerte". en E. Malvido, G. Pereira y V. Tiesler, (eds.) El Cuerpo Humano y su tratamiento mortuorio. México.pp.91-126.

Duday, H.; Guillon, M. (2006): "Understanding the Circumstances of Decomposition When the Body Is Skeletonized." Forensic Anthropology and Medicine: Complementary Sciences From Recovery to Cause of Death. Chapter 6. Edited by: A. Schmitt, E. Cunha, and J. Pinheiro. Humana Press Inc., Totowa, NJ

Fabián, J. F. (1995): El aspecto funerario durante el Calcolítico y los inicios de la Edad del Bronce en la Meseta Norte, Universidad de Salamanca.
Fabián, J.F. (2006): El IV y III milenio AC en el Valle del Amblés (Avila). Ar-queología de Castilla y León. Monografías 5. Junta de Castilla y León.

Fabián, J. F. y Blanco A. (2012): “Cuatro enterramientos calcolíticos en hoyo del Cerro de la Cabeza (Ávila)". Computum, 23, vol 1, 99-120.

Ferembach, D: (1974) “Techniques Anthropologiques. 1- Craniologie. Ecole pratique des hautes études. Laboratoire d'Anthropologie Biologique (Laboratoire BROCA)".

Fernández Eraso, J. y Mújika, J.A. (eds.) (2011): Actas del Congreso Internacional sobre Megalitismo y otras manifestaciones funerarias contemporáneas en su contexto social, económico y cultural. Munibe suplemento 32.

Fernández Eraso, J., Mújika, J.A. y Peñalver, X, (2011): "Hábitat y mundo funerario en la Prehistoria reciente del País Vasco: nuevas evidencias". En Fernández Eraso, J. y Mújika, J.A. (eds.): 250-269.

Flores, R. (2011): "El Yacimiento de Humanejos (Parla, Madrid)”. En Blasco, C., Liesau, C., y Ríos, P. (eds.): 9-16.

Flors, E. (2010): "Enterramientos neolíticos en Costamar (Ribera de Cabanes, Cabanes, Castellón)". En Pérez Fernández, A. y Soler, B.: Restos de Vida. Restos de muerte. Museu de Prehistoria de Valencia: 179-182.

García Puchol, O., Bernabeu, J., Carrión, y., Molina, LL., Pérez Jordà, G. y Gómez Puche, M. (2013): "A funerary perspective on Bell Beaker period in the Western Mediterranean. Reading the social context of individual burials at La Vital (Gandía, Valencia)". Trabajos de Prehistoria 70, No 2: 264277.

Gómez, J.L., Aliaga, R. (2010): “Tafonomías de inhumaciones múltiples en fondos calcolíticos del yacimiento del Camino de las Yeseras (San Fernando de Henares, Madrid)". En Gutiérrez-Redomero, E., Sánchez, A. y Galera, V. eds.), Diversidad Humana y Antropología Aplicada. Universidad de Alcalá; Alcalá de Henares, 489-498.

Gómez, J.L., Blasco, C., Trancho, G., Grueso, I., Ríos, P. y Martínez-Ávila, M. (2011): "Los protagonistas", En Blasco, C., Liesau, C y Ríos, P: (eds.), 101-132.

Gómez, J.L.y Grueso, I. (inédito): Estudio antropológico del fondo U.EX. 1461. Yacimiento Humanejos. (Parla, Madrid).

Goodman, A.H. y Rose, J-C. 1991: “Dental Enamel Hypoplasias as Indicators of Nutritional Status". En: Advances in Dental Anthropology. Willey-Liss, Inc. : 279-293.

Goodman, A.H., Armelagos, G.J. y Rose, J.C . (1980) : "Enamel hlypoplasias as indicators of stress in 
three prehistoric populations from Illinois". Human Biology 52: 515-528.

Guijo, J.M. y Lacalle, R. (2013): “Una reflexión metodológica acerca de los registros antropológicos de las inhumaciones del Tercer Milenio a.C. en el Aljarafe (Sevilla)" . En: García Sanjuan, L. Vargas Jiménez, J.M.; Hurtado Pérez, V.; Ruiz Moreno, T. Cruz-Auñón Briones (Eds.): El asentamiento prehistórico de Valencina de la Concepción (Sevilla). Universidad de Sevilla. Sevilla: 333-367.

Haglund, W.D. y Reay, D.T. (1993): "Problems of Recovering Partial Human Remains at Different Times and Locations: Sources for Death Investigator" Journal of Forensic Science, 38 : 6980.

Haglund, W.D. y Sorg, M.H. (1997): Forensic Taphonomy. The postmortem. Fate of Human Remains. CRC. Press, Florida.

Hurtado, V., Mondéjar, P. y Pecero, J.C. (2002): "Excavaciones en la Tumba 3 de La Pijotilla". Extremadura Arqueológica VIII : 249266.

Hutchinson D.L. y Spencer Larsen C. (1988): "Determination of stress episode duration from linear enamel hypoplasias: A case study from St. Catherines Island, Georgia". Hum. Biol. $60 \mathrm{n}^{\circ} 1$ : 93-110.

Iscan, M.Y.; Loth, S.L. y Wright R.K. (1987): "Racial variation in the sternal extremity of the rib and its effect on age determination". Journal of Forensic Sciences. Volume 32: 452-466

Knussmann R. (1986): “Anthropologie. Handbuch der vergleichenden Biologie des Menschen”. Band I: Wesen und Methoden der Anthropologie. Gustav Fischer Verlag. Stuttgart.

Liesau, C. (2011): "Los restos de mamíferos del ámbito doméstico y funerario. En: Blasco, C., Liesau, C. y Ríos, P. (eds.): 171-189.

Liesau, C. (2012): "Depósitos con ofrendas de animales en yacimientos Cogotas I: antecedentes y características". En: Rodríguez Marcos, J.A., Fernández Manzano, J. (Eds.), Cogotas I, Una cultura de la Edad del Bronce en la Península Ibérica. Homenajes a $M^{a}$ Dolores Fernández-Posse: 219257.

Liesau, C., Blasco, C., Ríos, P., Vega, J., Menduiña, R., Blanco, J. F., Baena, J., Herrera, T., Petri, A. y Gómez, J.L (2008): “Un espacio compartido por vivos y muertos: El poblado calcolítico de fosos de Camino de las Yeseras (San Fernando de Henares, Madrid)". Complutum, vol 18 (1): 97-120.

Liesau, C. y Schubart, H. (2006): "Construcciones funerarias y materiales de origen orgánico en el ritual funerario de Fuente Álamo". Spal, 15: 130143.
Lizcano, R., Cámara, J.A., Riquelme, J.A., Cañabate, Ma L., Sánchez, A. y Afonso, J.A. (1991-1992): “El polideportivo de Martos. Producción económica y símbolos de cohesión en un asentamiento del Neolítico Final en las Campiñas del Alto Guadalquivir". Cuadernos de Prehistoria de la Universidad de Granada 16-17: 5-101.

Lomba, J., López, M. y Ramos, F. (2009): “El enterramiento múltiple, calcolítico, de Camino del Molino (Caravaca, Murcia). Metodología y primeros resultados de un yacimiento excepcional", Trabajos de Prehistoria, 66-2, 143-159.

Lull, V., Micó, R., Rihuete, C. y Risch, R. (2010): "Límites históricos y limitaciones del conocimiento arqueológico: la transición entre los grupos arqueológicos de Los Millares y El Argar", en Bueno, P., Gilman, A., Martín Morales, C. y Sánchez Palencia, F. J. (eds): Arqueología, Sociedad, Territorio y Paisaje: estudios sobre Prehistoria Reciente, Protohistoria y transición al mundo romano, en homenaje a $M^{a}$ Dolores Fernández Posse, Biblioteca Praehistorica Hispana, XXVIII: 75-94.

Macarro, J.A. (2000): La Alcalá Prehistórica. El poblado de la edad del Bronce de la Dehesa. Alcalá de Henares.

Marquez, J.E. y Jiménez, V, (2010): Recintos de fosos. Genealogía y significado de una tradición en la Prehistoria del suroeste de la península Ibérica. (IV-III milenios AC). Universidad de Málaga.

Martin, R. y Saller, K. (1957): Lehrbuch der Anthroplogie in systematischer Darstelung mit besonderer Berücksichtigung der Anthropologischen Methoden. Gustav Fischer Verlag. Stuttgart.

Mendonça, M.C. de (2000): "Determinación de la talla a través de la longitud de los huesos largos". Am. J. Phys. Anthropol., 112 (1): 39-48.

Olivier, G. y Demoulin, F. (1984): Pratique anthropologique à l'usage des étudiants I. Osteologie. Université Paris: 7.

Pérez Jordá, G., Bernabeu, J., Carrión, Y, García, O., Molina, Ll. y Gómez, M. (eds.) (2011): La Vital (Gandía, Valencia). Vida y muerte en a desembocadura del Serpis durante el III y I milenio a.C. Diputación de Valencia.

Ramsey, C. B. (1995): "Radiocarbon calibration and analysis of stratigraphy: The Oxcal progmm". Radiocarbon, 37(2): 425-430.

Reimer, P.J., Baillie, M.G.L., Bard, E., Bayliss, A., Beck, J.W., Blackwell, P.G., Bronk Ramsey, C., Buck, C.E., Burr, G.S., Edwards, R.L., Friedrich, M., Grootes, P.M., Guilderson, T.P., Hajdas, I., Heaton, T.J., Hogg, A.G., Hughen, K.A., Kaiser, K.F., Kromer, B., McCormac, F.G., Manning, S.W., 
Reimer, R.W., Richards, D.A., Southon, J.R., Talamo, S., Turney, C.S.M., Van der Plicht, J. \&, (2009): "IntCal09 and Marine09 Radiocarbon Age Calibration Curves, 0-50,000 Years cal BP”, Radiocarbon, 51(4): 1111-1150.

Ríos, P. (2011): "Nuevas fechas para el Calcolítico de la región de Madrid. Aproximación cronocultural a los primeros poblados estables". En Blasco, C., Liesau, C. y Ríos, P. (eds.) : 73-86.

Ríos, P. (2013): "New dating of Bell Beaker horizon in the region of Madrid", P. Prieto Martinez \& L. Salanova: Current researches on Bell Beakers. Proceedings of the 15th International Bell Beaker Conference: From Atlantic to Ural. Santiago de Compostela: 97-110.

Ríos, P., Liesau. C., Aliaga, R. y Vega, J. (2012): "Estudio interdisciplinar de dos enterramientos calcolíticos del yacimiento de Camino de las Yeseras". Actas de las sexras jornadas de Patrimonio Arqueológico en la Comunidad de Madrid. Comunidad de Madrid: 279-294.

Rojo, M., Kunst, M., Garrido, R., García, I. y Morán, G. (2005): Un desafío a la eternidad. Tumbas monumentales en el Valle de Ambrona. Memorias. Arqueología de castilla y León 14.

Roselló, E. (2011): "Los peces". En: Blasco, C., Liesau, C y Ríos, P: (eds.): 235-236.
Scheuer L., Black, S. (2000): Developmental Juvenile Osteology. Academic Press, California.

Todd, T.W. (1920) "Age Changes in the pubic bone: I. The male white pubis". American Journal of Physical Anthropology. Volume 3, number 3: 285334

Ubelaker, D. (1989): Human Skeletal Remains. 2nd ed. Taraxacum Press, Washington, D.C.

Ubelaker, D. (2007): Enterramientos humanos, excavación, análisis, interpretación. Munibe. Suplemento 24.

Valera, A.C., Lago, M. Duarte, C. y Evangelista, L.S. (2000): “Ambientes funèrarios no complexo arqueológico dos Perdigoês: uma análise preliminar no contexto das práticas funerárias calcolíticasno Alentejo" Era Arqueológica,2: 84-105

VM, J., Blasco, C., Liesau, C., Ríos, P., Blanco, J. F., Menduiña, R., Aliaga, R., Moreno, E., Herrera, T., Petri, A. y Gómez, J.L. (2010): “La singular dualidad de enterramientos en el poblado de silos calcolítico de Camino de las Yeseras (San Fernando de Henares, Madrid)" Munibe. Suplemento 32: 648-662.

Weiss-Krejci, E. (2006): "Animals in morturary contexts of Neolithic and Chalcolithic Iberia", Animais na Pré-história e Arqueología da Península Ibérica. Actas do IV Congresso de Arqueología Peninsular: 35-45. 
